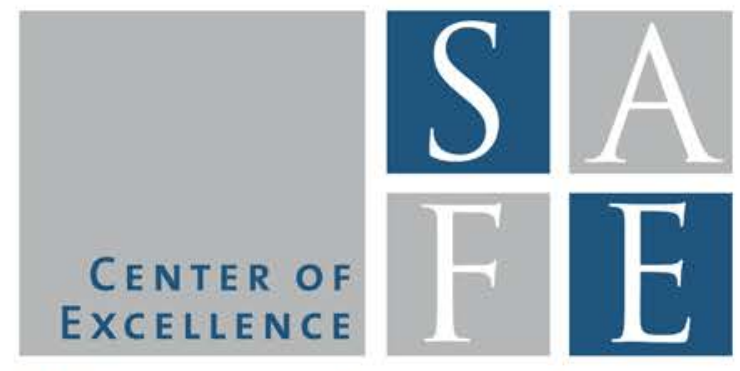

WORKING PAPER SERIES

Markku Kaustia - Elias Rantapuska

\title{
Does Mood Affect Trading Behavior?
}

SAFE Working Paper Series No. 4

Center of Excellence SAFE Sustainable Architecture for Finance in Europe A cooperation of the Center for Financial Studies and Goethe University Frankfurt 


\title{
Does Mood Affect Trading Behavior? *
}

\author{
MARKKU KAUSTIA \\ Aalto University \\ ELIAS RANTAPUSKA
}

Aalto University

November 9, 2012

We test whether investor mood affects trading with data on all stock market transactions in Finland, utilizing variation in daylight and local weather. We find some evidence that environmental mood variables (local weather, length of day, daylight saving and lunar phase) affect investors' direction of trade and volume. The effect magnitudes are roughly comparable to those of classical seasonals, such as the Monday effect. The statistical significance of the mood variables is weak in many cases, however. Only very little of the day-to-day variation in trading is collectively explained by all mood variables and calendar effects, but lower frequency variation seems connected to holiday seasons.

JEL-classification: D03, G11, G12

Keywords: mood, seasonal affective disorder (SAD), weather, trading behavior, stock market.

*Helsinki School of Economics is now part of Aalto University. Authors' mailing address: Aalto University, Department of Finance, P.O. BOX 21220, 00076 Helsinki, Finland. Tel: +358-41-5399450. E-mails: markku.kaustia@aalto.fi, elias.rantapuska@aalto.fi.. We thank Anders Anderson, Mark Kamstra, Lisa Kramer, Matti Keloharju, Timo Partonen and seminar participants at Aalto University, Maastricht University, University of Jyväskylä, the 5th Nordic Conference on Behavioral and Experimental Economics, and European Finance Association 2011 meeting for comments. We also thank Veera Murtomäki, Emilia Long, and especially Antti Lehtinen for excellent research assistance. Financial support from Okobank Group Research Foundation and Helsinki School of Economics Foundation is gratefully acknowledged. 


\section{Introduction}

Mood - a transient state of feeling at a particular time - can influence trading decisions if it affects expectations of future fundamentals, or interacts with risk preferences (Hirshleifer, 2001; Baker and Wurgler, 2007; DellaVigna, 2009). ${ }^{1}$ Consistent with this hypothesis, recent experimental studies find that people in a good mood are more likely to make riskier choices. ${ }^{2}$ However, results of laboratory studies may not always generalize to the field, due to differences in incentives, or other factors (Harrison, List and Towe, 2007). Furthermore, in addition to the question of the existence of a phenomenon, the question of its economic magnitude is important. The precise control available in an experimental setting may allow isolating an effect, while field evidence can provide a better means of assessing its economic significance.

This paper tests for the importance of mood effects in empirical field data consisting of investors' real stock market trades in Finland. We use external, medically validated mood variables, namely hours of daylight and local whether, to measure investor mood (See, e.g., Keller et al., 2005 and Papadopoulos et al., 2005 for medical evidence). These variables have also been found to be correlated with stock market returns (Saunders, 1993; Hirshleifer and

\footnotetext{
${ }^{1}$ People in a positive mood generally assess bad outcomes as being less likely compared to people in a negative mood (Johnson and Tversky, 1983; Wright and Bower, 1992). The affect infusion model (Forgas, 1995) predicts that a good mood should increase risk-taking and a negative mood should depress risk-taking if the current mood primes access to memories of mood congruent outcomes from risky choices. Forgas (1998) also finds that people in good moods are more likely to resort to heuristic rather than analytical decision-making.

${ }^{2}$ Yuen and Lee (2003), Chou, Lee, and Ho (2007), Knutson et al. (2008), Kuhnen and Knutson (2011), and others.
} 
Shumway, 2003; Kamstra, Kramer, and Levi, 2003). In addition, stock returns are lower during the days immediately following a daylight saving time change (Kamstra, Kramer, and Levi, 2000), when the temperature is high (Cao and Wei, 2005), as well as during the full moon (Yuan, Zheng, and Zhu, 2006). ${ }^{3}$ The current widespread explanation to the observed stock return effects is that they are due to the influence of mood on trading behavior. For example, Kamstra, Kramer, and Levi (2003) argue that seasonal affective disorder (SAD), a medical condition caused by a lack of sunlight, leads to more risk-averse behavior in the fall and winter.

To test whether investors' tendency to buy versus sell, as well as trading activity, is affected by these environmental mood variables, we employ a comprehensive dataset containing all trading records of all domestic investors in Finland during the period 1995-2002. We use the length of day, sunny weather, temperature, precipitation, daylight saving, and the lunar phase as mood variables. By selecting these variables, we limit ourselves to using those that have appeared in published studies finding stock return effects. This setting is ideal for studying the impact of environmental mood variables on trading behavior for three reasons.

${ }^{3}$ A second generation of studies confirming the earlier evidence on stock returns has emerged (See Kliger and Levy 2003; Garrett, Kamstra, and Kramer, 2005; Kamstra, Kramer, and Levi, 2007; Chang et al., 2008; Dowling and Lucey, 2008; Keef and Khaled, 2011; De Silva, Pownall, and Wolk, 2012; Kamstra, Kramer, Levi, and Wermers, 2012). Some critical studies have also appeared. The counter arguments include data mining, same seasonal return pattern explainable by many different mood-related variables, and econometric as well as datarelated problems (Goetzmann and Zhu, 2005; Jacobsen and Marquering, 2008; Kelly and Meschke, 2010). In addition, Bouman and Jacobsen (2002) and Loughran and Schultz (2004) note that a strong seasonal pattern in stock returns is not necessarily directly linked to any environmental mood factor despite correlation with a mood variable. 
First, Finland is located far up in the north and stretches 1,157 kilometers (719 miles) in the north-south dimension. There is consequently a great deal of variation in the length of day in the time series as well as in the cross-section. In northern Finland above the Artic Circle $\left(66^{\circ} 33^{\prime} \mathrm{N}\right)$, the sun does not set at all around the summer solstice and, correspondingly, does not rise around the winter solstice. Helsinki Exchanges (part of NASDAQ-OMX Group Plc) is the second northernmost stock exchange in the world, located on the $60^{\circ} 10^{\prime} \mathrm{N}$ latitude, a tad south of the Anchorage, Alaska $\left(61^{\circ} 13^{\prime} \mathrm{N}\right)$ latitude. The length of day around the summer solstice varies from 18.7 hours in southernmost Finland to 24 hours above the Artic Circle. Around the winter solstice, the length of day varies between zero in the north and 5.6 hours in the south.

Second, Finland has an area of 338,424 square kilometers, roughly the size of Germany, and comprises multiple climate zones. This provides for cross-sectional variation in local weather across the 455 municipalities in the country. For a visual representation of reasons 1) and 2), we refer to Figure 1 which shows a Mollweide map projection (maximum emphasis on having a correct projection of area at the expense of directions) of Finland, Europe and Eastern United States.

Third, sunlight deprivation is associated with depression in $9 \%$ of the Finnish population, a proportion having seasonal affective disorder (SAD), fatigue (subsyndromal-SAD, or SSAD) in about $39 \%$ of the population, and as much as $85 \%$ of the population report having had some seasonal changes in mood and behavior (Grimaldi et al., 2009). The prevalence ratios in Finland are high in comparison to international figures reported in Kelly and Meschke (2010): the average population prevalence of SAD is around 5\% and subsyndromal-SAD around $10 \%$ 
globally with mixed results on the impact of latitude on SAD and SSAD prevalence (Partonen and Magnusson, 2001).

For these reasons, we believe that, to the extent that mood changes caused by weather ("the weather hypothesis") or length of day have an impact on investor trading decisions ("the SAD hypothesis"), such effects should show up in the trading patterns of Finnish investors, if anywhere in the world. To measure the behavioral response of investors, we first classify investors into individuals, financial corporations (institutions) and other corporations. We exclude government bodies because of lack of variation in their location, and foreign investors because of missing data on their local weather conditions. We construct two behavioral outcome variables. First, we calculate a daily buy/sell ratio for each investor group in each municipality. Note that not all investor groups can simultaneously increase (or decrease) their buy/sell ratio because of a market level adding-up constraint. However, recall that we are excluding foreign investors (constituting approximately $45 \%$ of trading volume) and government bodies $(3-4 \%$ of trading volume), so the investor groups that we study in this paper can all trade in the same direction. Second, as an overall measure of stock market activity, we use the number of trades generated by each investor group.

We employ two econometric approaches in assessing the impact of mood variables. First, we run a municipality-level daily panel regression, with municipality and month fixed effects, on the buy/sell ratio. We find that the mood variables generally have the correct sign, and the effect 
magnitudes are comparable to classical seasonals, such as the Monday effect. ${ }^{4}$ For example, going from a full cloud cover to clear skies increases the buy/sell ratio of financial institutions by 1.6 percentage points. The effect is 0.8 percentage points for nonfinancial corporations and 0.3 percentage points for individual investors. Including the lagged value (yesterday's sunniness) boosts the effect, particularly for individuals. The full moon decreases the buy/sell ratio by 1.5 to 2.5 percentage points. Classical seasonals (Monday and Friday effects, turn of the month, turn of the year) do not generally surpass these magnitudes. The exceptions are the last five trading days of the year for financial institutions and the first five trading days of the year for individual investors. The statistical significance of the mood variables depends on the assumption one makes regarding the structure of the error terms in the panel. Most effects are highly statistically significant if we cluster standard errors along the municipality dimension. However, as will be discussed later, we lean toward implementing clustering in the time dimension, i.e., at the daily level. This renders the mood effects statistically insignificant in most cases, and the same is also true for many of the classical seasonal effects.

\footnotetext{
${ }^{4}$ The literature on stock market calendar effects is extensive. The findings include anomalous return effects at the turn of the year (Rozeff, 1976; Reinganum, 1983), the turn of the month (Ariel, 1987; Lakonishok and Smidt, 1988; Xu and McConnell, 2008), and for different days of the week (French, 1980; Gibbons and Hess, 1981). Thaler (1987a, 1987b) provides a survey of the early literature. See Grimbacher, Swinkels, and Van Vliet (2010) for recent evidence combining several different effects.
} 
Second, we use the following approach to identify the effect of SAD. ${ }^{5}$ We run a crosssectional regression on detrended buys versus sells for each day (or, alternatively, each week). This constitutes a tough but precise test. The SAD hypothesis predicts that lack of exposure to daylight leads to higher risk aversion and selling stocks. Thus, at a given point in time, investors in areas having a shorter day should be more prone to selling stocks than investors living in areas with a longer day. We find that the length of day has the correct sign $(+)$ in regressions on buys versus sells for individual investors and nonfinancial corporations. It is statistically significant only in the case of daily regressions for individuals where $53 \%$ of the coefficients are positive. The effect on trading volume is positive for all investor groups and statistically significant in most specifications. Some patterns we observe are inconsistent with the SAD hypothesis. For example, we find that individuals living in northern Finland tend to buy stocks during the darkest months of the year. We also utilize this cross-sectional technique for an alternative estimate of the impact of sunniness. When we limit our analysis to days with significant cross-country variation in weather, we find that the relation between sunniness and the tendency to buy stocks is positive $53 \%$ of the time for individuals, $51 \%$ of the time for nonfinancial corporations and $52 \%$ of the time for financial corporations. None of those results are statistically significant, however.

We find that there is considerable seasonal variation in both the total trading volume and the propensity to buy versus sell that seems unconnected to the length of day and sunniness.

\footnotetext{
${ }^{5}$ The effect of a slowly and deterministically moving variable such as the length of day cannot be meaningfully identified in the daily panel regression.
} 
Individual investors sell relatively more stocks and trade less during the holiday season. Institutions experience a similar effect in trading volume, but their propensity to buy versus sell increases gradually from January to December. These findings are broadly consistent with the holiday hypothesis introduced by Bouman and Jacobsen (2002).

Is investor mood a significant driver of trading behavior? We have attempted to provide as careful and neutral an investigation as possible in the case of environmental mood factors. Whether one considers the glass half full or half empty depends on how the pieces of evidence are weighted, which is ultimately something for the reader to decide. We do offer our own interpretation, but defer the discussion until the concluding Section 5 of the paper. In what follows, we present the data in more detail in Section 2 and discuss the key measures and econometric identification. In Section 3, we discuss the main results and in Section 4 we discuss additional results and robustness checks.

\section{Data and methodology}

\subsection{Data sources}

Our core data come from the Finnish Central Securities Depositary (FCSD), which maintains an electronic and official register of all securities transactions in Finland for virtually all companies listed in the Helsinki Exchanges (HEX, nowadays a part of NASDAQ-OMX). The data comprise daily trading account records of all Finnish investors and the sample period runs from January 1, 1995 through November 28, 2002, a period that includes both bull and bear markets. More detailed information on a subset of the data can be found in Grinblatt and Keloharju (2000). 
The second key dataset is from the Finnish Meteorological Institute (FMI), which supplies data on temperature (in Celsius), precipitation (in $\mathrm{mm}$ ) and sunniness (index taking values from 1 to 10$),{ }^{6}$ all measured at noon. The weather data cover the entire FCSD data sample period, but with some gaps. There are 135 weather observation stations in Finland and we measure the weather condition of each municipality using the closest station. ${ }^{7}$ We choose the closest weather station by computing the distance between the station and the center of gravity (centroid) of the municipality. Having on average 3.3 municipalities per weather station is a potential source of cross-correlation. In panel regressions, we alleviate the effect of this and other possible sources by clustering the standard errors over the time unit of observation.

We use stock price data from the Helsinki Exchanges and collect daylight saving changes (as in Kamstra, Kramer, and Levi, 2000) and lunar cycles (as in Yuan, Zheng, and Zhu, 2006) from a website maintained by the University of Helsinki (http://almanakka.helsinki.fi). Descriptive statistics are reported in Table 1 . We have 1.2 million investors, 445 municipalities and 13 million trades in our base data. In our panel regressions we, however, always exclude daily and weekly observations for municipalities with fewer than 5 trades by an investor group to reduce the number of extreme observations.

${ }^{6}$ From the FMI, we have a cloudiness variable between 0 and 8 indicating the number of quadrants ( 8 in all) entirely covered by clouds and not visible from the ground. When the clouds cannot be observed from the ground due to thick fog or a heavy snowstorm, for example, the variable takes the value of 9 and in practice it is almost always completely cloudy in such cases. For ease of exposition, we reverse the scale to achieve a measure of sunniness that takes values from 1 to 10 , with 10 indicating a clear sky.

${ }^{7}$ There are 445 municipalities after excluding 10 due to mergers during the sample period. 
Finally, we also contact all Finnish municipalities by letter during June-September 2011 to enquire about their primary school $\left(1^{\text {st }}\right.$ to $9^{\text {th }}$ grade) holiday periods during the sample period. Although the broad holiday seasons are congruent across the country (around Christmas and from early June until mid-August), municipalities set the exact schedules. We obtain school holiday data on $236(53 \%)$ of the municipalities. Missing data on the rest of the municipalities is in most cases due to their failure to centrally maintain these records from 9 to 16 years back.

\subsection{Measurement}

We first aggregate trades on municipality and investor group level (individuals, nonfinancial, and financial corporations). We compute the buy/sell ratio based on the number of transactions (\# of buys/\# of buys and sells). Then, for each municipality and investor group, we consider daily (and, alternatively, weekly) buy/sell ratios. For each investor group in municipality $i$ on day or week $t$ :

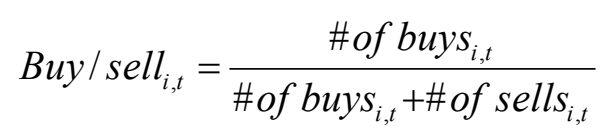

We also compute trading volume by summing up the number of trades and take natural logarithm for a measure of trading volume. We split investors into individuals and institutions in our descriptive analyses. In more granular municipality level regression analyses, we further split institutional investors into nonfinancial and financial corporations. Government and nonprofit organizations, as well as mutual and pension funds, are excluded because they have rather limited geographical variation in trades: only $8 \%$ of municipalities have 1,000 trades or more by government and nonprofit institutions during the entire sample period, while $3 \%$ of 
municipalities have at least 1,000 trades for mutual and pension funds. Foreigners trading in the Finnish stock market have the option to register their stockholdings in their own name or via a domestic financial institution using a nominee account. We can identify neither their physical location nor the weather and length of day they are exposed to, so we exclude them from the analysis.

We calculate the length of day from sunrise to sunset (photoperiod in medical terms) with the CBM model which is most suitable for extreme latitudes (equations 1-3 in Forsythe et al., 1995). This method accounts for the refraction of sunlight through atmosphere. For example, the sun can be perfectly visible, although de facto below the horizon. The correction due to refraction is not always trivial as it varies by latitude and time of year. At a maximum the effect is 75 minutes for municipalities on $66^{\circ} \mathrm{N}$ during the winter solstice.

To give a perspective on the time series and cross-sectional variation in the amount of daylight, Figure 2 shows on the map of Finland the length of day on the winter and summer solstice (around December 21 and June 21) and spring and fall equinox (around March 21 and September 21). To give a perspective on the geographical dispersion of the trades, Figure 3 plots the number of trades for both individual and institutional investors on the map of Finland. Although the trades are concentrated in metropolitan areas, there is a good amount of crosssectional variation outside urban areas for both investor groups.

\subsection{Identification}

Our identification strategy consists of two sets of analyses. The first one uses daily panel regressions run at municipality-level. Of the three environmental mood variables (sunniness, 
lunar phase, length of day), we include the first two in these regressions. We do not investigate the length of day with this method because it is a persistent variable that changes deterministically from one day to the next. The change is almost linear within most months, although of course nonlinear throughout the whole year. We therefore investigate the effect of SAD with purely cross-sectional regressions (discussed later) as well as in univariate analysis of seasonal trends. ${ }^{8}$ The panel regression models, estimated with OLS, are of the following form:

$$
\begin{aligned}
& Y_{i, t}=\alpha+\beta \text { Environmental factors } \text { fi,t }+\delta \text { Calendar controls } \\
& +\varphi \text { Municipality fixed effect }+\gamma \text { Month fixed effect }+\varepsilon_{i, t}
\end{aligned}
$$

where the dependent variable $Y_{i, t}$ is either the buy/sell ratio or log number of trades, $i$ indexes municipalities and $t$ indexes time periods (days or weeks). The environmental factors vector includes sunniness ( 1 for inability to see sky, 10 for clear sky), full moon dummy (value of 1 for full moon), demeaned temperature (in Celsius), ${ }^{9}$ daylight saving dummy for Mondays with a daylights saving change during the preceding weekend, and demeaned precipitation (in $\mathrm{mm}$ ). The calendar controls vector includes separate dummies for the first five, and last five, trading days of the year, a Monday (or after holiday) dummy, Friday (or before holiday) dummy, as well

\footnotetext{
${ }^{8}$ If we do, nevertheless, include the SAD variable in the panel regressions, it gets a zero coefficient.

${ }^{9}$ To remove pure seasonal variation in temperature and precipitation, we deduct the average temperature during the week of the observation within the 8-year sample period from the daily observation in a given municipality (i.e., an average calculated over $5 \times 8=40$ days). We apply the same procedure for precipitation. The rationale for this is the significant seasonal variation: temperature, for example, varies from -44 degrees Celsius (-47 degrees Fahrenheit) to +32 degrees Celsius (90 degrees Fahrenheit). Without demeaning, these highly seasonal weather variables would mainly capture the time of the year (See also Jacobsen and Marquering, 2008, for discussion).
} 
as a dummy for the last 3 and $1^{\text {st }}$ trading days of the month. These calendar variables are included based on studies documenting anomalous return effects at the turn of the year (Rozeff, 1976; Reinganum, 1983), turn of the month (Ariel, 1987; Lakonishok and Smidt, 1988), and for different days of the week (Gibbons and Hess, 1981).

All specifications include municipality and month fixed effects. This removes the potential effects of unobserved time invariant heterogeneity at the municipality level. The month effects remove the impact of slow-moving seasonals and market trends. We only include observations where an investor group has at least 5 trades in the municipality to reduce the skewness of the dependent variable. Since we use daily data, the dependent variables (buy/sell ratio or log number of trades) contain important daily effects due to market level news. There is also a common national component in the environmental variables. We account for the resulting crosssectional dependence by time-clustering the standard errors at the daily level. ${ }^{10}$

The second set of analyses that we run are geared toward identifying the effect of SAD via cross-sectional variation in the length of day. We do this by implementing a two-step approach. First, we identify the municipality-specific level and time trend and remove it from the data. Specifically, we estimate the following model separately with weekly and daily data for each municipality $i$ :

\footnotetext{
${ }^{10}$ Alternatively, cross-sectional (municipality level) clustering could be used. This results in $t$-statistics that are 2-4 times higher compared to those obtained with time clustering, and very close to regular White standard errors. This implies that the time effects are much more important in the data, in line with our intuition.
} 


$$
\text { Buy/sell } l_{i, t}=\alpha_{i}+\beta_{i}^{1} T+\beta_{i}^{2} T^{2}+\varepsilon_{i, t}
$$

where $T$ is the time index variable. Similarly, for trading volume:

$$
\operatorname{Ln}(\text { Numberof trades })_{i, t}=\alpha_{i}+\beta_{i}^{1} T+\beta_{i}^{2} T^{2}+\varepsilon_{i, t}
$$

We then use the residuals from (3) and (4) as the dependent variable. These residuals (denoted excess buy/sell and excess volume) now exclude the municipality-specific constant $\left(\alpha_{i}\right)$ as well as the linear and squared time trend unique to each municipality. In the second step, we estimate for each time period $t$ (weeks or days) the following models with OLS:

$$
\begin{aligned}
& \text { Excessbuy/sell } l_{i, t}=\alpha_{t}+\lambda_{t} \text { Lengthof day in hours }_{i, t}+\varepsilon_{i, t} \\
& \text { Excessvolume }_{i, t}=\alpha_{t}+\lambda_{t} \text { Lengthof day in hours }_{i, t}+\varepsilon_{i, t}
\end{aligned}
$$

Although the effect of sunniness is already tested in the panel regressions, we estimate a similar cross-sectional model also for sunniness as an alternative test:

$$
\begin{gathered}
{\text { Excessbuy } / \text { sell }_{i, t}}=\alpha_{i, t}+\lambda_{t} \text { Sunniness }_{i, t}+\varepsilon_{i, t} \\
\text { Excess volume }_{i, t}=\alpha_{t}+\lambda_{t} \text { Sunniness }_{i, t}+\varepsilon_{i, t}
\end{gathered}
$$

These tests identify the effects solely through their variation across the country at a given point in time. Seasonal or municipality-specific effects do not directly influence these estimates as all time series and municipality-level variation has been removed. We are interested in the distribution of the coefficients $\square_{t}$. If these environmental mood variables affect trading, more than half of the coefficients should be positive. 


\section{Results}

In this section, we first discuss descriptive evidence on the buy/sell ratio and trading volume. This is relevant, particularly for assessing the lower frequency implications of the SAD hypothesis. In the second subsection, we discuss results from daily panel regressions with observations at municipality-level where we simultaneously control for all environmental variables as well as calendar effects. Then, in the third subsection, we discuss results from crosssectional regressions aimed at identifying SAD.

\subsection{Descriptive analysis}

We begin by plotting the excess number of buys and sells throughout the year for an eyeball test of any obvious patterns in the data. Panel A of Figure 4 shows a clear pattern of domestic individual investors selling stocks during the summer months (May-July) and purchasing stocks during the fall months (August-October). For institutions, we observe a different pattern: a gradually increasing buy/sell ratio over the course of the year. These major patterns are not fully consistent with either the original SAD specification in Kamstra, Kramer, and Levi (2003), nor the later refinement introduced in Kamstra, Kramer, and Levi (2007).

Rather, on aggregate, the trading by individuals seems to be connected to vacations at weekly intervals (Bouman and Jacobsen, 2002; Hong and Yu, 2009). Summer vacations are fairly long in Finland by international standards: full-time employees are entitled to a summer leave of about four weeks, and many have 5 to 6 weeks. July is by far the most popular month for summer holidays. The trading patterns of individual investors thus coincide quite well with the vacation season: people sell stocks before and during their summer holidays, and also early 
December, just prior to the end-of-year holiday season, and then buy stocks afterwards. This is consistent with the idea that the household sector partially finances the increased consumption during the summer vacation and the end-of-year season by net sales of publicly traded stock.

Some of the minor patterns do lend support to the SAD hypothesis. Kamstra, Kramer, and Levi (2003) predicts selling pressure by SAD investors around December, when the length of day is at its shortest. This is the case in the aggregate sample (Panel A). However, the aggregate results are driven by individuals in southern Finland (Panel C). The behavior of individuals living in northern Finland (Panel B) with the greatest variation in daylight during the year is again inconsistent with the SAD hypothesis: these individuals buy rather than sell stocks during the darkest months.

The "onset/recovery" measure, designed to account for the time variation in SAD prevalence in Kamstra, Kramer, and Levi (2007) predicts buying by investors who do not yet suffer from $\mathrm{SAD}$ during August-October, and selling from investors who still suffer from SAD during February-April. ${ }^{11}$ Consistent with this idea, there is excess buying from both individuals and institutions during August-October, and the effect is stronger for individuals located in northern Finland. During February-April, however, we observe a systematic selling pattern only for institutions.

${ }^{11}$ Saarijärvi, Lauerma, Helenius, and Saarilehto (1999) report that in Finland SSAD and SAD onset risk peaks in October and November with offset in March and April. These patterns are similar in the US (Young, 1997; Lam, 1998). We also obtain more recent data from the Finnish Health 2000 survey (data described in Heistaro, 2008, p. 118), and based on these data we observe the onset risk to peak in October and November, with a decline during the holiday month of December and another peak in January, after which onset risk starts to decline. 
We now turn to investigate patterns in trading volume. Figure 5 plots the weekly fraction of trading volume (number of trades in a municipality/annual number of trades), a measure that would equal $1 / 52=0.0192$ throughout the year if there was no variation in trading volume. The result is a clear seasonal pattern: trading volume declines for both individuals and institutions significantly during the holiday months of May-August with a trough in July, the most popular summer holiday month. If investors are suffering from $\mathrm{SAD}$, one would perhaps expect them to trade less during the winter months when they may fall into apathy, as pointed out by Kelly and Meschke (2010). However, this is not what we observe for the full sample, nor do we find any clear trend between latitude deciles.

In Figure 6, we plot the average weekly fraction of trading volume as a function of the length of day. There is a strong downward slope for both individuals $(\rho=0.66-0.67)$ as well as institutions $(\rho=0.45-0.46)$, indicating that people trade less when the day is longer. The unconditional relation is unrelated to latitude - congruent with the holiday hypothesis.

In sum, the descriptive analysis lends little support to the SAD hypothesis with the original Kamstra, Kramer, and Levi (2003) specification, but when the data are interpreted with the lenses of onset/recovery measure, there is some, albeit on aggregate, mixed evidence to support the SAD hypothesis. Instead, the aggregate evidence from seasonal trading patterns is by and large consistent with the holiday hypothesis.

\subsection{Panel regressions}

Table 2 reports descriptive statistics for the panel sample and Table 3 shows the results for panel regressions with four specifications for both buy/sell and trading volume with three 
investor groups. The coefficient estimate for the sunniness variable is positive for all investor groups. Perhaps surprisingly, the highest value (0.0017) is for financial corporations, implying a 1.7 percentage point increase in the buy/sell ratio when going from a full cloud cover to clear skies. The corresponding effect for nonfinancial corporations is 0.8 percentage points. These effect sizes are similar to that of Mondays which decrease the buy/sell ratio by 0.6 to 2.5 percentage points, depending on investor group. The impact of sunny weather is not statistically significant, however: the highest $t$-statistic is 1.5 for nonfinancial corporations. ${ }^{12}$ Furthermore, the effect is the smallest for individual investors ( 0.3 percentage points), the group of investors that is thought to be most susceptible to the influence of variations in mood.

The full moon variable also has the right sign (negative) across the buy/sell specifications, with $t$-values between 1.3 and 1.6 in the baseline (column 1) models, indicating a statistically weak relation. Statistical significance exceeds the $10 \%$ threshold for individual investors when we add temperature and daylight savings in column 2 . It further exceeds the $5 \%$ level in column 3 , but this specification uses only about half of the observations due to missing values (we discuss this later). Once again, the effect magnitudes are comparable to classical seasonals: full moon decreases the buy/sell ratio by 1.5 to 2.5 percentage points in the baseline model, thus having approximately the same impact as a weekday being a Friday.

${ }^{12}$ As discussed earlier, these regressions employ standard errors clustered at the daily level. The $t$-statistics grow by a factor of 2 to 4 if, instead, we cluster along the municipality dimension. The statistical significance as well as the magnitude of sunniness are often - though not universally - increased if we add its lagged value, i.e., yesterday's sunniness. We discuss this as well as other robustness checks in Section 4. 
Of the other weather variables, the results have the correct sign for precipitation $(-)$ and mixed for daylight saving (correctly negative for individuals and nonfinancial corporations) in buy/sell regressions. The sign for temperature $(+)$ is inconsistent with the negative stock return effect found in Cao and Wei (2005). The negative precipitation effect is significant for individuals and financial corporations. The data loss in this specification (column 4) is due to only about $20 \%$ of the weather stations recording precipitation. The estimated coefficient for precipitation implies quite sizable effects. For example, consider a day with a precipitation of 10 millimeters $(0.4 \mathrm{inch})$ above the average daily amount of $1.4 \mathrm{~mm}$. This corresponds to a typical amount in a rainy day. The buy/sell ratio of individuals would then be 1.9 percentage points below the mean. The effect is even larger for financial corporations at 3.7 percentage points. Including precipitation also drives out any effect there was due to the sunniness variable. These results imply a significant effect from going from sunny skies to rain clouds. However, the majority of the effect is produced by rain, not by lack of sunlight.

The only significant volume effect is due to daylight-saving change. This effect reduces trading volume by $9.5 \%$ for individuals and by $17.8 \%$ for financial corporations. The effect on nonfinancial corporations is insignificant $(-4.5 \%, t$-value 1.6$)$.

The calendar control variables are all relevant for trading behavior, but their statistical significance, as well as the direction of influence, varies according to investor group. Individual investors and nonfinancial corporations engage in significant selling on Fridays. Financial corporations sell heavily on Mondays. The other two investor groups also do this, but the effect is not statistically significant for them. The fact that all three groups of investors trade in the same direction on Mondays implies that the omitted group, foreign investors, are net buyers on 
Mondays. Individuals buy stocks heavily in the first five trading days of the year, but the last five trading days of the year show no effects for the direction of trading. Financial corporations engage in heavy selling in the last five trading days of the year. For all investor groups, trading volume increases significantly around the turn of the year, and decreases on Mondays. These results complement the large stream of literature that documents calendar patterns in stock returns but that does not analyze trading behavior (See footnote 5 for references to some of this literature).

In the third column of Table 3, we also report results for a subsample containing a variable indicating whether primary schools (grades 1 through 9) in the municipality were closed. Virtually all of the variation is due to differences in school schedules, rather than unscheduled school closings (due to bad weather, for example), which are extremely rare in Finland. ${ }^{13}$ Hence, we dub this variable "vacation". The results show that financial institutions reduce their trading activity by $7 \%$ when schools are out, but there are no other significant effects in the data. A failure to find an effect for individuals could be due to measurement error and lack of statistical power. First, whereas a bank's trader is very unlikely to trade on the bank's account when he or she is on vacation, individual investors are not similarly constrained. Second, individuals might not be switching between trading mode and abstaining completely from trading in perfect congruence with school holidays. In this case, our identification that is only utilizing the small differences in school schedules between the municipalities, and controlling for lower frequency

\footnotetext{
${ }^{13}$ Finland does not experience tornadoes or hurricanes, but snowstorms causing traffic problems are possible. However, schools still stay open and students as well as teachers are present.
} 
effects with month fixed effects, could be missing the effect. Thus, it seems that only the longer holiday seasons are relevant for aggregate trading activity, as indicated by the descriptive analysis earlier.

To facilitate the assessment of overall economic significance, the bottom part of each panel in Table 3 presents adjusted R-squared figures from three different models: containing municipality fixed effects only, municipality and month fixed effects, and the full model for which the coefficient estimates are shown. As expected, the municipality fixed effects go a long way in explaining variation in trading volume, but not as far in explaining the buy/sell ratio. Time effects add most explanatory power for individual investors. Comparison of the full model to the one with municipality and time-fixed effects shows that the traditional calendar effects and the mood variables collectively only slightly enhance the R-squares: the improvement in the case of the buy/sell ratio is 0.09 to 0.22 percentage points, and even smaller for trading volume. As an alternative measure, we first subtract the sum of squares explained by municipality and monthfixed effects, and then look at the percent of remaining variation explained. This paints a slightly rosier picture in the case of trading volume where the fixed effects already explain a lion's share. Even so, the traditional calendar effects and the mood variables together in the baseline model only explain less than $0.5 \%$ of the remaining variation.

\subsection{Cross-sectional regressions}

In this section, we move on to a scrutinizing test of the SAD hypothesis (excess buy/sell is related to length of day) by way of purely cross-sectional identification. We do this because identifying a slow-moving length of day effect is problematic in a daily panel regression. We 
also utilize this technique for a further test of the weather hypothesis with sunniness variable which was nevertheless already tested using the panel regressions. For tests of SAD, we exclude weeks just around each equinox (weeks 12-14 and 38-40) when the length of day is close to 12 hours in the entire country. ${ }^{14}$

Table 4 reports descriptive statistics and Table 5 shows the estimation results. Overall, the results provide some support for SAD affecting the direction of trade for individuals: $53 \%$ of daily regressions have a positive coefficient on the length of day, and this is statistically significantly different from 50\% (z-value 2.4). However, the corresponding figure from weekly regressions $(52 \%)$ is insignificant. The results regarding trading volume are clearly more robust: longer days are associated with higher trading volume for all investor groups in both weekly and daily data. The coefficient is positive in $51-59 \%$ of the volume regressions and statistically significant in 5 of 6 specifications.

The coefficients for financial corporations' daily buy/sell regressions have negative signs both on the length of day and sunniness ( $t$-values of -3.04 and -2.21 ), counter to the SAD and weather hypotheses. Financial corporations also seem to trade less on sunnier days: the coefficient in volume regression is positive in only $46 \%$ of the daily regressions.

\footnotetext{
${ }^{14}$ Results estimated with these weeks in the sample are virtually identical, however. In an unreported analysis, we also estimate the length of day regressions using only weeks between the equinoxes (1-11 and 41-53) due to a practice in medical research on SAD to concentrate generally on the fall and winter seasons. The results are very similar to those reported.
} 
Evidence for the weather hypothesis is somewhat weaker than for the SAD hypothesis, as shown by coefficients for sunniness in Table 5 . We also entertain the possibility that we do not detect the impact of sunny weather because all observations are pooled into one regression and the cross-sectional variation of weather can be small in some days or weeks. This is also motivated by Watson (2000, p. 95): "It is possible ... that significant mood effects can be identified only when more extreme weather phenomena are examined.” Table 6 reports daily results for sunniness when we only consider the top quintile of observations with most betweenmunicipality variation in sunniness. For individuals, the coefficient for sunniness is positive in $53 \%$ of regressions, which is not statistically significantly different from $50 \%$. For nonfinancial and financial corporations, the coefficient for excess buy/sell regression is positive in $51-52 \%$ of the time, also not statistically significant.

One of the strongest conclusions in the medical literature on SAD is that women are more affected than men, although men are more likely to experience other major depressive disorders (e.g., Partonen and Lönnqvist, 1998; Saarijärvi et al., 1999). Odds ratios up to 16:1 have been reported in extreme cases for female versus male prevalence of SAD (e.g., Hellekson, 1989). Motivated by these findings, we report in Table 7 cross-sectional results separately for men and women. In line with the prediction from the medical literature, the results are stronger for women with $52 \%$ of positive coefficients (vs. $51 \%$ for men) for a daily excess buy/sell regression, but the difference is not statistically significant. However, we find the opposite pattern in weekly data and also mixed results for trading volume. 
Taken together, the results from these cross-sectional analyses reported in Tables 5 through 7 do not show clear support for the impact of sunniness and the length of day on the direction of trade. There is, however, evidence that the length of day is associated with more trading activity.

\section{Robustness checks}

Our dependent variables of interest (buy/sell, buy/sell volume) are persistent, especially volume. Therefore, if sunny weather increases buying, its total effect might take the form of a decaying impulse. In this case, controlling for the lagged dependent variable would reduce the estimated contemporaneous effect of sunniness. On the other hand, if the sun only affects such a component of trading behavior that does not carry over to the next period, then controlling for the lagged dependent variable can be appropriate to reduce noise. In an unreported analysis, we add the lagged dependent variable, and find that this has very little effect on the results. Estimates are generally slightly lower compared to the baseline which offers some support for the decaying impulse mechanism.

In another unreported analysis, we run all the regressions with only the mood variable of interest (sunniness or moonlight) and no calendar control variables, but including month fixed effects as usual. If the effects are statistical artifacts of a limited sample arising from some confounding seasonality (for example, suppose that during our sample period, Mondays would happen to be more cloudy than other days), the estimates for the mood variables might be stronger without controls. On the other hand, if the mood effects are genuine, controlling for the known seasonal effects (as we do in the baseline regressions) should lead to more precise 
estimates for the mood variables. We find that the $t$-statistics for the mood variables are indeed slightly lower when we drop the seasonal controls, but the differences to the baseline specification are small. The negative daylight savings effect on trading volume becomes significant at the $5 \%$ level for nonfinancial corporations, bringing it in line with other investor groups for which the effect is significant with or without calendar controls.

The weather variables are measured once a day at noon. This is naturally an imperfect representation of the whole day's weather. In an attempt to capture the afternoon weather, we run the regressions including a lead (tomorrow's value) of the explanatory variables. It is, of course, impossible for realized future weather to have a direct effect on today's trading behavior. It is, however, possible that the forecast of tomorrow's weather would have some effect on today's trading behavior. Tomorrow's realized value of a weather variable is correlated with today's forecast (one would certainly hope that this is the case with weather forecasts). For example, a trader who, on Thursday, learns that some very nice weather is in store for Friday, might plan her work schedule so that she is able to leave work early the next day. This might involve working late and trading more on Thursday. Therefore, by including the lead, we capture a proxy of the current day's afternoon whether, as well as a proxy for weather-related expectations. We find that an $F$-test for the sum of the coefficients (current and lead) does not lead to material changes in inference compared to the baseline analysis. 
We also investigate potential lagged weather effects. ${ }^{15}$ Including the lagged value generally increases the significance of sunniness. For individuals, the $t$-values of the lagged variable range from 1.70 to 1.93 in the buy-sell regressions, and are over 2.0 in the trading volume regressions. The negative effect of sunshine on trading volume, evaluating the lagged, lead and contemporaneous coefficients jointly, is significant at the $1 \%$ level. The volume effects for nonfinancial corporations are also in many cases significant at the 5\% level. For financial institutions the results are similar to the baseline results.

Some regressors, such as sunniness and temperature, as well as the dependent variables, are likely to contain persistent shocks. ${ }^{16}$ Time-clustered standard errors and the inclusion of fixed municipality effects in the baseline panel regressions may not completely eliminate a resulting downward bias in the standard errors. As a check of robustness, we estimate a panel data model that allows contemporaneous correlations between municipalities, and includes a common autoregressive (order one) error process in the time dimension. Similar to the baseline panel regression, this allows utilizing both time series and cross-sectional variation, while providing an alternative method for addressing serial dependence. We do not include a full set of month

${ }^{15}$ The evidence in the psychology literature of a possible lagged effect of weather on mood is mixed. Persinger (1975) finds a lagged effect up to two days, but Sanders and Brizzolara (1982) do not find any such effects using a larger data sample.

${ }^{16}$ In contrast to sunniness, lunar phase is perfectly aligned around the whole world, and so the identification comes exclusively from the time series effect. The lunar cycle is about 29.5 days and we have 103 observations of the full moon during the sample period. We use a single day dummy for the full moon, so this regressor is not persistent. 
effects in this specification to ease the computational burden, but rather use a dummy for each calendar month and year.

The unreported results show that, compared to the baseline panel regressions, the $t$-statistic for the full moon dummy is now somewhat higher (at 2.0) for individuals, and similar to the baseline for other investor groups. Like the baseline results, the impact of sunniness is statistically insignificant, but now it also has the wrong sign (-) for individuals and nonfinancial corporations. There is a negative and significant Friday effect for all investor groups, as well as a negative and significant Monday effect for both types of corporations, but not for individuals. The patterns around the turn of the year are similar to the baseline results: financial corporations sell during the last five trading days of the year, and individual investors buy during the first five trading days of the year. However, the estimated standard errors are larger compared to the baseline regressions, leading to marginal statistical significance ( $t$-statistic 1.82 in both cases).

The calendar month dummies included in this approach allow further insight into the lower frequency variation over the year. Consistent with "Sell in May and go away" (See Bouman and Jacobsen, 2002), the buy/sell ratios are two to six percentage points lower in the month of May, and these effects are statistically significant for individuals as well as financial institutions. Individuals also live up to the other part of the rule, and "buy back in St. Leger's day" (in September) or by the time of Halloween (in October). The estimates are about 3.5 for both of these month dummies and highly statistically significant. 


\section{Conclusion}

This paper started by asserting that Finland provides a great setting for testing whether mood has an impact on investors' trading behavior. The results show that sunniness has a positive effect on the demand for stocks, and a full moon has a negative effect, consistent with the studies that associate these variables with stock returns. Also, precipitation and daylight saving effects have the predicted negative signs, but temperature does not. However, the effects are in most cases statistically insignificant or only borderline significant in our admittedly conservative statistical tests. We find little evidence of seasonal affective disorder (SAD) affecting the tendency to buy versus sell, but there is evidence of a positive effect on the volume of trade. The clearest patterns in the aggregate trading data seem to be connected to holiday seasons, as well as the turn of the year. Investors trade less during holidays overall, and trade in a direction consistent with financing vacation-related consumption.

Alternative to focusing on statistical significance, one can compare the environmental mood variables with classical calendar effects (such as the Monday effect), on which there is a large stream of literature. The effect magnitudes are by and large the same. By way of Bayesian statistical inference, a reasonable prior might be that the classical seasonal effects are real. Hence, also the environmental mood effects could turn out statistically significant when being evaluated jointly across multiple samples in future studies.

The total impact of all the mood variables as well as the traditional calendar effects combined - as evidenced by their contribution to model adjusted R-squared - is very small, however. Thus, we conclude that from the standpoint of overall economic significance, neither day-to-day mood 
changes unconnected to any fundamentals nor the classical calendar effects seem to exert a major influence on investors' trading decisions.

The variables that we study can be thought of as instruments of investor sentiment. Yet, we hesitate to draw any conclusions between the findings of this study and the broader role of sentiment in financial markets. Different mechanisms are likely to be at play when sentiment is affected by more salient events, builds over a longer term, interacts with fundamentals (as with the cross-section of firm characteristics and stock returns), or has a social element. For example, Edmans, Garcia and Norli (2007) find a negative stock market reaction following soccer World Cup losses. Kaplanski and Levy (2010) show that aviation disasters lead to large immediate negative market reactions that reverse in the course of the following weeks. These papers argue that the market effects are brought about by sudden changes in investor mood. Such discrete events may have stronger effects on trading behavior than the more mundane changes in the environment that we study. ${ }^{17}$ The hypothesized mechanism is still the same: exogenous events impact investors' mood, leading to changes in optimism or risk aversion, or both, which in turn affect trading decisions. Along the lines of this paper, where we have limited our study to environmental mood variables, an analysis applied to these discrete events would also be interesting.

To our knowledge, this is the first paper to study the effect of mood on trading behavior with comprehensive data. However, we may not be aware of unpublished work finding weak results

\footnotetext{
${ }^{17}$ Strictly speaking, daylight-saving time switch or sudden changes in weather do represent discrete changes. However, contrary to major sports events or disasters, such effects are still normally very mundane.
} 
between mood and trading behavior, or no results between other potential environmental factors and asset prices, given that many well crafted papers with no significant results may end up unpublished, and thus never reach a wider audience. 


\section{References}

Ariel, R.A., 1987. A Monthly Effect in Stock Returns. Journal of Financial Economics 18, 161174.

Baker, M., Wurgler, J., 2007. Investor Sentiment and Stock Returns. Journal of Economic Perspectives 21(2), 129-151.

Bouman, S., Jacobsen, B., 2002. The Halloween Indicator, "Sell in May and Go Away": Another Puzzle. American Economic Review 92 (4), 1618-1635.

Cao, M.,Wei, J., 2005. Stock market returns: A Note on Temperature Anomaly. Journal of Banking and Finance 29 (6), 1559-1573.

Chan, S.C., Chen, S.S., Chou, R.K., Lin, Y-H., 2008. Weather and Intraday Patterns in Stock Returns and Trading Activity. Journal of Banking and Finance 32 (9), 1754-1766.

Chou, K.L., Lee, T.M.C., Ho, A.H.Y., 2007. Does Mood State Change Risk Taking Tendency in Older Adults? Psychology and Aging 22, 310-318.

De Silva, D.G., Pownall, R.A.J., Wolk, L., 2012. Does the sun 'shine' on art prices? Journal of Economic Behavior and Organization 82, 167-178.

DellaVigna S., 2009. Psychology and Economics: Evidence from the Field. Journal of Economic Literature 47, 315-372.

Dowling, M., Lucey, B.M., 2008. Robust Global Mood Influences in Equity Pricing. Journal of Multinational Financial Management 18, 145-164.

Edmans, A., García, D., Norli, Ø., 2007. Sports Sentiment and Stock Returns. Journal of Finance 62 (4), 1967-1982.

Forgas, J.P., 1995. Mood and judgment: The Affect Infusion Model (AIM). Psychological Bulletin 117, 39-66.

Forgas, J.P., 1998. On Being Happy And Mistaken: Mood Effects on the Fundamental Attribution Error. Journal of Personality and Social Psychology 75, 318-331.

Forsythe, W.C., Rykiel, E.J., Stahl, R.S., Wu, H., Schoolfield, R.M., 1995. A Model Comparison for Daylight as a Function of Latitude and day of Year. Ecological Modeling 80, 87-95.

French, K., 1980. Stock Returns and the Weekend Effect. Journal of Financial Economics 8, 5569.

Garrett, I., Kamstra, M.J., Kramer, L.A., 2005. Winter Blues and Time Variation in the Price of Risk. Journal of Empirical Finance 12, 291-316.

Gibbons, M.R., Hess, P., 1981. Day of the Week Effects and Asset Returns. Journal of Business 54, 579-596.

Goetzmann., W., Zhu, N., 2005. Rain or Shine: Where is the Weather Effect? European Financial Management 11 (5), 559-578. 
Grimaldi S., Partonen T., Haukka J., Aromaa A., Lönnqvist J., 2009. Seasonal Vegetative and Affective Symptoms in the Finnish General Population: Testing the Dual Vulnerability and Latitude Effect Hypotheses. Nordic Journal of Psychiatry 63, 397-404.

Grimbacher, S.B., Swinkels, L.A.P., Van Vliet, P., 2010. An Anatomy of Calendar Effects. SSRN Working Paper no. 1593770.

Grinblatt, M., Keloharju, M., 2000. The Investment Behavior and Performance of Various Investor Types: A Study of Finland's Unique Data Set. Journal of Financial Economics 55, 43-67.

Harrison, G.W., List, J.A., Towe, C., 2007. Naturally Occurring Preferences and Exogenous Laboratory Experiments: A Case Study of Risk Aversion. Econometrica 75, 433-458.

Heistaro, S, (Ed.), 2008. Methodology Report, Health 2000 Survey. Publications of the National Public Health Institute, KTL B 26/2008.

Hellekson C., 1989. Phenomenology of Seasonal Affective Disorder: An Alaskan Perspective. In: Rosenthal N, Blehar M, toim. Seasonal Affective Disorder and Phototherapy. New York: Guilford Press, pp. 33-45.

Hirshleifer, D., Shumway, T., 2003. Good day Sunshine: Stock Returns and the Weather. Journal of Finance 58 (3), 1009-1032.

Hirshleifer, D., 2001. Investor Psychology and Asset Pricing. Journal of Finance 56, 1533-1597.

Hong, H., Yu, J., 2009. Gone Fishin': Seasonality in Trading Activity and Asset Prices. Journal of Financial Markets 12, No. 4, 672-702.

Jacobsen, B., Marquering, W.A., 2008. Is it the Weather? Journal of Banking and Finance 32 (4), 526-540.

Johnson, E.J., Tversky, A., 1983. Affect, Generalization and the Perception of Risk. Journal of Personality and Social Psychology 45, 20-31.

Kamstra M.J., Kramer, L.A., Levi, M.D., 2000. Losing Sleep at the Market: The Day-LightSaving anomaly. American Economic Review 90, 1005-1011.

Kamstra M.J., Kramer, L.A., Levi, M.D., 2003. Winter Blues: A SAD Stock Market Cycle, American Economic Review 93 (1), 324-343.

Kamstra M.J., Kramer, L.A., Levi, M.D., 2007. Opposing Seasonalities in Treasury versus Equity Returns. Rotman School of Management Working Paper No. 1076644.

Kamstra, Mark J., Kramer, Lisa A., Levi, Maurice D. and Wermers, Russ R., 2012, "Seasonal Asset Allocation: Evidence from Mutual Fund Flows", SSRN Working Paper.

Kaplanski, G., Levy, H., 2010. Sentiment and Stock Prices: The Case of Aviation Disasters. Journal of Financial Economics 95(2), 174-201.

Keef, S.P, Khaled, M.S., 2011. Are Investors Moonstruck? Further International Evidence on Lunar Phaces and Stock Returns. Journal of Empirical Finance 18, 56-63. 
Keller, M.C., Fredrickson, B.L., Ybarra, O., Côte, S., Johnson, K., Mikels, J., Conway, A., Wager, T., 2005. A Warm Heart and a Clear Head. Psychological Science 16 (9), 724-731.

Kelly, Patrick J., Meschke, F., 2010. Sentiment and Stock Returns: The SAD Anomaly Revisited. Journal of Banking and Finance 34 (6), 1308-1326.

Kliger, D., Levy, O., 2003. Mood-induced Variation in Risk Preferences. Journal of Economic Behavior and Organization 52, 573-584.

Knutson, B., Wimmer, G.E., Kuhnen, C.A., Winkielman, P., 2008. Nucleus Accumbens Activation Mediates the Influence of Reward Cues on Financial Risk Taking. NeuroReport 19, 509-513.

Kuhnen, C.A., Knutson, B., 2011. The Influence of Affect on Beliefs, Preferences and Financial Decisions. Journal of Financial and Quantitative Analysis 46, 605-626.

Lakonishok, J., Smidt, J., 1988. Are Seasonal Anomalies Real? A Ninety-Year Perspective. Review of Financial Studies 1 (4), 403-425.

Lam, R.W., 1998. Seasonal Affective Disorder: Diagnosis and Management. Primary Care Psychiatry 4, 63-74.

Loughran, T., Schultz, P., 2004. Weather, Stock Returns and the Impact of Localized Trading Behavior. Journal of Financial and Quantitative Analysis 39, 343-363.

Papadopoulos F.C., Frangakis C.E., Skalkidou A., Petridou E., Stevens R.G., Trichopoulos D., 2005. Exploring Lag and Duration Effect of Sunshine in Triggering Suicide. Journal of Affective Disorders 88, 287-297.

Partonen, T., Lönnqvist, J., 1998. Seasonal Affective Disorder. The Lancet 352, 1369-1374.

Partonen, T., Magnusson, A. (Eds.), 2001. Seasonal Affective Disorder: Practice and Research. New York, Oxford University Press, 2001.

Persinger, M.A., 1975. Lag Response in Mood Reports to Changes in the Weather Matrix. International Journal of Biometeorology 19, 108-114.

Reinganum, M.R., 1983. The Anomalous Stock Market Behavior of Small Firms in January: Empirical Tests for Tax-Loss Selling Effects. Journal of Financial Economics 12, 89-104.

Rozeff, M.S., Kinney Jr., W.R., 1976. Capital Market Seasonality: The Case of Stock Returns. Journal of Financial Economics 3, 379-402.

Saarijärvi, S., Lauerma, H., Helenius, H., Saarilehto, S., 1999. Seasonal Affective Disorders among Rural Finns and Lapps. Acta Psychiatrica Scandinavica 99, 99-105.

Sanders, J.L., Brizzolara, M.S., 1982. Relationships between Weather and Mood. Journal of General Psychology 107, 155-156.

Saunders, E.M., 1993. Stock Prices and Wall Street Weather. American Economic Review 83 (5), 1337-1345. 
Thaler, R.H., 1987a. Amomalies: The January Effect. Journal of Economic Perspectives 1, 197201.

Thaler, R.H., 1987b. Anomalies: Seasonal Movements in Security Prices II: Weekend, Holiday, Turn of the Month, and Intraday Effects. Journal of Economic Perspectives 1, 169-177.

Watson, D., 2000. Mood and Temperament. Guilford Press, New York

Wright, W.F., Bower, G.H., 1992. Mood Effects on Subjective Probability Assessments. Organizational Behavior and Human Decision Processes 52, 276-291.

Xu, W., McConnell, J.J., 2008. Equity Returns at the Turn-of-the-Month. Financial Analysts Journal 64, 49-64.

Young, M., Meaden, L., Fogg, L., Cherin, E., Eastman, C., 1997. Which Environmental Variables are Related to the Onset of Seasonal Affective Disorder? Journal of Abnormal Psychology 106, 554-562.

Yuan, K., Zheng, K., and Zhu, Q., 2006. Are Investors Moonstruck? Lunar Phases and Stock Returns. Journal of Empirical Finance 13 (1), 1-23.

Yuen, K.S.L., Lee, T.M.C., 2003. Could Mood State Affect Risk-Taking Decisions? Journal of Affective Disorders 75, 11-18. 
Table 1

\section{Descriptive statistics on the investor data}

This table presents descriptive statistics on the panel data where the unit of observation is municipality with daily data from January 1, 1995 through November 28, 2002. In subsequent descriptive analyses, trades by institutional investors are aggregated into one group. In regression analyses, only individual investors, nonfinancial corporations and financial corporations are considered.

Panel A: Number of investors and trades in the base sample

Number of domestic investors in the sample

$1,178,333$

Number of individual investors

$1,119,406$

Number of institutional investors

45,855

Number of nonfinancial corporations

Number of financial corporations

Number of trades by domestic investors in the sample

by individual investors

7.2 million

by institutional investors

by nonfinancial corporations

2.34 million

by financial corporations

3.49 million

Value of trades by domestic investors in the sample

by individual investors

52.7 billion

by institutional investors

by nonfinancial corporations

128.42 billion

by financial corporations

300.37 billion

Panel B: Municipality statistics

Number of municipalities in Finland in 1995

Number of municipalities removed from sample due to merger

Number of municipalities with never 5 or more trades per day 
Table 2

\section{Descriptive statistics on the municipality-level as used in panel regression}

The sample includes all trades by domestic investors (individuals, nonfinancial corporations and financial corporations) during the sample period of 1995-2002. There is one observation for each municipality/day, and 444 municipalities in total. To enter the sample, the municipality must have at least 5 trades by the investor group on the given day. Panel A presents statistics for the dependent variables. Panel B presents the statistics for independent variables using the valid observations from individual investors. Other investor groups have slightly different values due to missing some municipalities. Buy/sell is defined as \# of buys / (\# of buys and sells). Sunniness takes the value of 1 for days when sky cannot be observed and 10 for clear sky. Full moon is a dummy for full moon days. Last 5 trading days of the year, First 5 five trading days of the year, Monday or after holiday, Friday or before holiday, and Last 3 and $1^{\text {st }}$ trading of month are self-explanatory calendar dummy variables. Daylight saving dummy takes the value of 1 if during the preceding weekend (daylight saving changes always happen on Sundays). Precipitation is the amount of rain in $\mathrm{mm}$.

\begin{tabular}{|c|c|c|c|c|c|c|c|c|}
\hline & Min & Mean & Median & Max & St.dev. & Skewness & Kurtosis & $\mathrm{N}$ \\
\hline \multicolumn{9}{|l|}{ Panel A. Dependent variables } \\
\hline \multicolumn{9}{|l|}{ Individuals } \\
\hline Buy/sell & 0.00 & 0.51 & 0.50 & 1.00 & 0.26 & -0.04 & 2.47 & 200,597 \\
\hline \# of trades & 5.00 & 35.78 & 11.00 & 4569.00 & 136.70 & 12.79 & 228.90 & 200,597 \\
\hline \multicolumn{9}{|l|}{ Nonfinancial corporations } \\
\hline Buy/sell & 0.00 & 0.51 & 0.50 & 1.00 & 0.27 & 0.01 & 2.44 & 44,488 \\
\hline \# of trades & 5.00 & 52.58 & 10.00 & 3017.00 & 187.80 & 6.57 & 53.23 & 44,488 \\
\hline \multicolumn{9}{|l|}{ Financial corporations } \\
\hline Buy/sell & 0.00 & 0.50 & 0.50 & 1.00 & 0.30 & 0.01 & 2.39 & 6,866 \\
\hline \# of trades & 5.00 & 508.70 & 13.00 & 7669.00 & 1067.49 & 2.46 & 8.50 & 6,866 \\
\hline \multicolumn{9}{|c|}{ Panel B. Independent variables } \\
\hline Sunniness (index) & 1.00 & 4.23 & 3.00 & 10.00 & 2.55 & 0.86 & 2.32 & 200,597 \\
\hline Full moon dummy & 0 & 0.04 & 0 & 1 & 0.19 & 4.89 & 24.91 & 200,597 \\
\hline Last 5 trading days of year & 0 & 0.02 & 0 & 1 & 0.15 & 6.55 & 43.85 & 200,597 \\
\hline First 5 trading days of year & 0 & 0.03 & 0 & 1 & 0.16 & 6.03 & 37.33 & 200,597 \\
\hline After holiday dummy & 0 & 0.21 & 0 & 1 & 0.41 & 1.41 & 2.98 & 200,597 \\
\hline Before holiday dummy & 0 & 0.23 & 0 & 1 & 0.42 & 1.31 & 2.72 & 200,597 \\
\hline Turn of the month dummy & 0 & 0.17 & 0 & 1 & 0.38 & 1.75 & 4.06 & 200,597 \\
\hline Temperature, Celsius & -44.40 & 6.16 & 5.20 & 31.80 & 10.41 & -0.12 & 2.63 & 200,597 \\
\hline Daylight saving dummy & 0 & 0.01 & 0 & 1 & 0.09 & 11.32 & 129.20 & 200,597 \\
\hline Precipitation, $\mathrm{mm}$ & 0 & 1.65 & 0.40 & 44.90 & 3.07 & 3.78 & 25.18 & 39,386 \\
\hline Vacation & 0 & 0.25 & 0 & 1 & 0.43 & 1.13 & 2.28 & 105,925 \\
\hline
\end{tabular}


Table 3

\section{Results from panel regressions for environmental mood variables and calendar effects}

The depended variable is buy/sell ratio based on trade count, or (zero skewness log) number of trades. The base sample includes all trades by domestic investors in all Finnish stocks during the sample period of 1995-2002. There is one observation for each municipality/day combination and the sample is divided into domestic individuals, nonfinancial corporations and financial corporations. To enter the sample, the municipality must have at least 5 trades by the investor group on the given day and be in the sample of 444 municipalities (10 municipalities are excluded due to merger, other missing municipalities are due to having fewer than 5 trades). Sunniness takes the value of 1 for days when sky cannot be observed and 10 for clear sky. Full moon is a dummy for full moon days. Last 5 trading days of the year First 5 five trading days of the year, Monday or after holiday, Friday or before holiday, and Last 3 and $1^{\text {st }}$ trading of month are self-explanatory calendar dummy variables. Daylight saving dummy takes the value of 1 if during the preceding weekend (daylight savings always happen on Sunday) there was a daylight saving change. Temperature (Celsius) and Precipitation (millimeters) are demeaned by subtracting the municipality's average for that week of the year. Vacation is a dummy indicating if $1^{\text {st }}$ to $9^{\text {th }}$ grade primary schools were closed in the municipality on the trading day. All specification include municipality and month fixed effects as well as a constant term, and they are estimated with OLS. Absolute values of $t$-statistics based on standard errors clustered at the daily level are reported below coefficients. Adjusted R-squared figures are reported for three different models: using only municipality fixed effects (Muni FE Only) on the same sample as the reported specification, using municipality and month-fixed effects (Muni and time FE), and for the full model for which the coefficients are shown in the table (Full model). Increase, $p p$. gives the improvement in the adjusted R-squared in percentage points when going from Muni and time FE to Full model. Remaining var. explained gives the adjusted R-squared for the full model after subtracting the sum of squares explained by municipality and month-fixed effects. Asterisks mark statistical significance: $* * *$ for $1 \%, * *$ for $5 \%$, and $*$ for $10 \%$. 


\begin{tabular}{|c|c|c|c|c|c|c|c|c|}
\hline \multicolumn{9}{|l|}{ Panel A: Individuals } \\
\hline \multirow{3}{*}{ Sunniness } & \multicolumn{4}{|c|}{ Buy/sell count } & \multicolumn{4}{|c|}{ Ln number of trades } \\
\hline & 0.0003 & 0.0003 & 0.0003 & -0.0001 & -0.0022 & -0.002 & -0.0023 & -0.0042 \\
\hline & 0.50 & 0.51 & 0.50 & 0.08 & 1.63 & 1.51 & 1.60 & 1.55 \\
\hline \multirow[t]{2}{*}{ Full moon } & -0.0177 & -0.0182 & -0.0203 & -0.0104 & -0.0145 & -0.0138 & -0.0285 & -0.0518 \\
\hline & 1.63 & $1.66^{*}$ & $2.01 * *$ & 0.76 & 0.49 & 0.47 & 0.93 & 1.20 \\
\hline \multirow[t]{2}{*}{ Last 5 days of year } & 0.0023 & 0.0029 & 0.006 & -0.0075 & 0.0839 & 0.08 & 0.0792 & 0.0782 \\
\hline & 0.17 & 0.21 & 0.41 & 0.49 & $2.56^{* *}$ & $2.48 * *$ & $2.16^{* *}$ & $1.77^{*}$ \\
\hline \multirow[t]{2}{*}{ First 5 days of year } & 0.0369 & 0.0363 & 0.037 & 0.0301 & 0.1608 & 0.163 & 0.1716 & 0.1512 \\
\hline & $2.47 * *$ & $2.43 * *$ & $2.36 * *$ & 1.56 & $5.3 * * *$ & $5.3 * * *$ & $5.0 * * *$ & $3.6 * * *$ \\
\hline \multirow[t]{2}{*}{ Monday or after holiday } & -0.0063 & -0.0056 & -0.0059 & -0.0027 & -0.0301 & -0.0271 & -0.0291 & -0.04 \\
\hline & 1.37 & 1.21 & 1.19 & 0.45 & $2.81 * * *$ & $2.50 * *$ & $2.48^{* *}$ & $2.56^{* *}$ \\
\hline \multirow[t]{2}{*}{ Friday or before holiday } & -0.0178 & -0.0178 & -0.0152 & -0.0146 & 0.0256 & 0.0253 & 0.0253 & 0.0225 \\
\hline & $3.25 * * *$ & $3.26 * * *$ & $2.73 * * *$ & $2.09 * *$ & $2.25 * *$ & $2.22 * *$ & $1.98 * *$ & 1.42 \\
\hline \multirow[t]{2}{*}{ Last 3 and 1 st day of $\mathrm{m}}$. & -0.0041 & -0.004 & -0.0051 & -0.0058 & -0.015 & -0.0152 & -0.0135 & -0.0349 \\
\hline & 0.81 & 0.79 & 0.97 & 0.87 & 1.33 & 1.35 & 1.09 & $2.10 * *$ \\
\hline \multirow[t]{2}{*}{ Temperature (demeaned) } & & 0.0002 & 0.0005 & 0.0009 & & -0.0017 & -0.002 & -0.0011 \\
\hline & & 0.63 & 1.22 & 1.59 & & $1.75^{*}$ & $1.98 *$ & 0.67 \\
\hline \multirow[t]{2}{*}{ Daylight saving } & & -0.0186 & -0.0167 & -0.0447 & & -0.0947 & -0.0979 & -0.0644 \\
\hline & & 0.98 & 0.75 & 1.92 & & $2.40 * *$ & $2.31 * *$ & 1.07 \\
\hline \multirow[t]{2}{*}{ Vacation } & & & -0.0051 & & & & 0.0038 & \\
\hline & & & 0.85 & & & & 0.25 & \\
\hline \multirow[t]{2}{*}{ Precipitation (demeaned) } & & & & -0.0019 & & & & 0.0003 \\
\hline & & & & $3.05 * *$ & & & & 0.20 \\
\hline Number of observations & 200,597 & 200,597 & 105,925 & 39,386 & 200,597 & 200,597 & 105,925 & 39,386 \\
\hline Number of municipalities & 444 & 444 & 236 & 144 & 444 & 444 & 236 & 144 \\
\hline \multicolumn{9}{|l|}{ Adj. R-squared for: } \\
\hline - Muni FE only & $2.79 \%$ & $2.79 \%$ & $3.27 \%$ & $2.91 \%$ & $58.70 \%$ & $58.70 \%$ & $62.04 \%$ & $72.14 \%$ \\
\hline - Muni and time FE & $11.48 \%$ & $11.48 \%$ & $12.42 \%$ & $12.35 \%$ & $75.98 \%$ & $75.98 \%$ & $79.50 \%$ & $84.38 \%$ \\
\hline - Full model & $11.61 \%$ & $11.62 \%$ & $12.55 \%$ & $12.53 \%$ & $76.06 \%$ & $76.07 \%$ & $79.59 \%$ & $84.47 \%$ \\
\hline Increase, $\mathrm{pp}$ & 0.13 & 0.14 & 0.13 & 0.18 & 0.08 & 0.09 & 0.09 & 0.09 \\
\hline Remaining var. explained & $0.15 \%$ & $0.16 \%$ & $0.15 \%$ & $0.21 \%$ & $0.33 \%$ & $0.37 \%$ & $0.44 \%$ & $0.58 \%$ \\
\hline
\end{tabular}




\begin{tabular}{|c|c|c|c|c|c|c|c|c|}
\hline \multicolumn{9}{|c|}{ Panel B: Nonfinancial corporations } \\
\hline \multirow{3}{*}{ Sunniness } & \multicolumn{4}{|c|}{ Buy/sell count } & \multicolumn{4}{|c|}{ Ln number of trades } \\
\hline & 0.0009 & 0.0008 & 0.0008 & -0.0003 & -0.0019 & -0.0018 & 0.0000 & -0.005 \\
\hline & 1.48 & 1.39 & 0.99 & 0.20 & 1.41 & 1.34 & 0.02 & 1.35 \\
\hline \multirow[t]{2}{*}{ Full moon } & -0.0145 & -0.0154 & -0.0213 & -0.0024 & -0.0053 & -0.005 & 0.0081 & -0.0187 \\
\hline & 1.51 & 1.59 & 1.90 & 0.15 & 0.25 & 0.24 & 0.32 & 0.42 \\
\hline \multirow[t]{2}{*}{ Last 5 days of year } & 0.0072 & 0.0095 & 0.0116 & 0.0115 & 0.0596 & 0.0573 & 0.0551 & 0.0493 \\
\hline & 0.55 & 0.73 & 0.70 & 0.53 & $2.31 * *$ & $2.23 * *$ & $1.85 *$ & 1.3 \\
\hline \multirow[t]{2}{*}{ First 5 days of year } & 0.0046 & 0.0025 & 0.0005 & 0.0046 & 0.0833 & 0.0847 & 0.0872 & 0.0765 \\
\hline & 0.29 & 0.16 & 0.03 & 0.24 & $3.18 * * *$ & $3.23 * * *$ & $2.70 * * *$ & $1.93^{*}$ \\
\hline \multirow[t]{2}{*}{ Monday or after holiday } & -0.0066 & -0.0058 & -0.0014 & -0.0099 & -0.0697 & -0.0682 & -0.0681 & -0.0901 \\
\hline & 1.55 & 1.34 & 0.27 & 1.49 & $7.58 * *$ & $7.28 * *$ & $6.13 * *$ & $5.80 * *$ \\
\hline \multirow[t]{2}{*}{ Friday or before holiday } & -0.0158 & -0.0157 & -0.0169 & -0.0143 & -0.0099 & -0.0101 & -0.0123 & -0.0328 \\
\hline & $3.6 * * *$ & $3.56 * * *$ & $3.32 * * *$ & $2.15^{* *}$ & 1.08 & 1.11 & 1.15 & $2.02 * *$ \\
\hline \multirow[t]{2}{*}{ Last 3 and 1 st day of $\mathrm{m}}$. & -0.0111 & -0.0109 & -0.0154 & -0.0098 & -0.0137 & -0.0138 & -0.0149 & -0.0203 \\
\hline & $2.38 * *$ & $2.35 * *$ & $2.89 * * *$ & 1.46 & 1.43 & 1.44 & 1.34 & 1.09 \\
\hline \multirow[t]{2}{*}{ Temperature (demeaned) } & & 0.0009 & 0.0011 & 0.002 & & -0.0009 & -0.0007 & 0.0024 \\
\hline & & $2.27 * *$ & $2.20 * *$ & $2.89 * * *$ & & 1.03 & 0.68 & 1.54 \\
\hline \multirow[t]{2}{*}{ Daylight saving } & & -0.021 & -0.0294 & -0.0412 & & -0.0455 & -0.0322 & -0.0424 \\
\hline & & 1.03 & $1.68 *$ & $2.69 * * *$ & & 1.56 & 0.77 & 0.80 \\
\hline \multirow[t]{2}{*}{ Vacation } & & & 0.0012 & & & & -0.0067 & \\
\hline & & & 0.17 & & & & 0.42 & \\
\hline \multirow[t]{2}{*}{ Precipitation (demeaned) } & & & & -0.0006 & & & & -0.003 \\
\hline & & & & 0.75 & & & & 1.56 \\
\hline Number of observations & 44,488 & 44,488 & 25,259 & 11,173 & 44,488 & 44,488 & 25,259 & 11,173 \\
\hline Number of municipalities & 354 & 354 & 191 & 107 & 354 & 354 & 191 & 107 \\
\hline \multicolumn{9}{|l|}{ Adj. R-squared for: } \\
\hline - Muni FE only & $2.58 \%$ & $2.58 \%$ & $2.42 \%$ & $3.68 \%$ & $71.76 \%$ & $71.76 \%$ & $77.93 \%$ & $77.59 \%$ \\
\hline - Muni and time FE & $3.90 \%$ & $3.90 \%$ & $3.98 \%$ & $5.31 \%$ & $77.54 \%$ & $77.54 \%$ & $82.99 \%$ & $84.81 \%$ \\
\hline - Full model & $3.99 \%$ & $4.01 \%$ & $4.12 \%$ & $5.43 \%$ & $77.60 \%$ & $77.60 \%$ & $83.03 \%$ & $84.88 \%$ \\
\hline Increase, $\mathrm{pp}$ & 0.09 & 0.11 & 0.14 & 0.12 & 0.06 & 0.06 & 0.04 & 0.07 \\
\hline Remaining var. explained & $0.09 \%$ & $0.11 \%$ & $0.15 \%$ & $0.13 \%$ & $0.27 \%$ & $0.27 \%$ & $0.24 \%$ & $0.46 \%$ \\
\hline
\end{tabular}




\begin{tabular}{|c|c|c|c|c|c|c|c|c|}
\hline \multicolumn{9}{|c|}{ Panel C: Financial corporations } \\
\hline \multirow{3}{*}{ Sunniness } & \multicolumn{4}{|c|}{ Buy/sell count } & \multicolumn{4}{|c|}{ Ln number of trades } \\
\hline & 0.0017 & 0.0016 & 0.0023 & -0.0025 & -0.0042 & -0.0041 & -0.0039 & -0.004 \\
\hline & 1.17 & 1.09 & 1.24 & 0.62 & 1.52 & 1.47 & 1.27 & 0.47 \\
\hline \multirow[t]{2}{*}{ Full moon } & -0.0251 & -0.025 & -0.0118 & -0.0229 & 0.0306 & 0.0295 & 0.0046 & 0.0028 \\
\hline & 1.26 & 1.25 & 0.54 & 0.63 & 0.96 & 0.92 & 0.13 & 0.04 \\
\hline \multirow[t]{2}{*}{ Last 5 days of year } & -0.1025 & -0.1014 & -0.0546 & -0.109 & 0.0174 & 0.0168 & 0.0936 & 0.0992 \\
\hline & $3.72 * * *$ & $3.68 * * *$ & 1.62 & $2.50 * *$ & 0.27 & 0.26 & 1.51 & 1.06 \\
\hline \multirow[t]{2}{*}{ First 5 days of year } & -0.0057 & -0.006 & 0.0565 & 0.0052 & 0.179 & 0.1776 & 0.1149 & 0.1388 \\
\hline & 0.19 & 0.21 & 1.32 & 0.13 & $3.10^{* * *}$ & $3.06^{* * *}$ & $1.99 * *$ & 1.38 \\
\hline \multirow[t]{2}{*}{ Monday or after holiday } & -0.0251 & -0.027 & -0.0219 & -0.0268 & -0.1077 & -0.1019 & -0.1025 & -0.0915 \\
\hline & $2.94 * * *$ & $3.12^{* * *}$ & $2.04 * *$ & $1.77^{*}$ & $6.26^{* * *}$ & $5.85^{* * *}$ & $5.15^{* * *}$ & $3.13^{* * *}$ \\
\hline \multirow[t]{2}{*}{ Friday or before holiday } & 0.0004 & 0.0007 & -0.0107 & -0.0181 & -0.0109 & -0.0111 & -0.0107 & 0.0087 \\
\hline & 0.05 & 0.08 & 1.01 & 1.22 & 0.70 & 0.71 & 0.59 & 0.31 \\
\hline \multirow[t]{2}{*}{ Last 3 and 1 st day of m. } & -0.0037 & -0.0037 & -0.0217 & -0.0023 & -0.0108 & -0.0107 & 0.0229 & -0.0454 \\
\hline & 0.42 & 0.42 & $1.86^{*}$ & 0.14 & 0.62 & 0.61 & 1.14 & 1.42 \\
\hline \multirow[t]{2}{*}{ Temperature (demeaned) } & & 0.0007 & 0.0003 & 0.0002 & & -0.0003 & -0.0011 & -0.0006 \\
\hline & & 0.64 & 0.22 & 0.12 & & 0.16 & 0.49 & 0.15 \\
\hline \multirow[t]{2}{*}{ Daylight saving } & & 0.0637 & 0.0448 & -0.0115 & & -0.1783 & -0.0797 & -0.1169 \\
\hline & & 1.73 & 1.03 & 0.13 & & $3.08 * * *$ & 1.01 & 0.89 \\
\hline \multirow[t]{2}{*}{ Vacation } & & & -0.0075 & & & & -0.0703 & \\
\hline & & & 0.44 & & & & $2.26^{* *}$ & \\
\hline \multirow[t]{2}{*}{ Precipitation (demeaned) } & & & & -0.0037 & & & & 0.0012 \\
\hline & & & & $2.10 * *$ & & & & 0.28 \\
\hline Number of observations & 6,866 & 6,866 & 3,544 & 2,008 & 6,866 & 6,866 & 3,544 & 2,008 \\
\hline Number of municipalities & 174 & 174 & 87 & 52 & 174 & 174 & 87 & 52 \\
\hline \multicolumn{9}{|l|}{ Adj. R-squared for: } \\
\hline - Muni FE only & $8.27 \%$ & $8.27 \%$ & $10.67 \%$ & $10.04 \%$ & $89.50 \%$ & $89.50 \%$ & $92.62 \%$ & $92.44 \%$ \\
\hline - Muni and time FE & $9.29 \%$ & $9.29 \%$ & $12.32 \%$ & $11.32 \%$ & $93.42 \%$ & $93.42 \%$ & $96.50 \%$ & $95.51 \%$ \\
\hline - Full model & $9.51 \%$ & $9.52 \%$ & $12.42 \%$ & $11.53 \%$ & $93.45 \%$ & $93.45 \%$ & $96.53 \%$ & $95.52 \%$ \\
\hline Increase, $\mathrm{pp}$. & 0.22 & 0.23 & 0.10 & 0.21 & 0.03 & 0.03 & 0.03 & 0.01 \\
\hline Remaining var. explained & $0.24 \%$ & $0.25 \%$ & $0.11 \%$ & $0.24 \%$ & $0.46 \%$ & $0.46 \%$ & $0.86 \%$ & $0.22 \%$ \\
\hline
\end{tabular}


Table 4

Descriptive statistics for cross-sectional analysis

This table presents descriptive statistics on the pooled panel data where the unit of observation is municipality with daily and weekly data from January 1, 1995 through November 28, 2002. The data are used in the cross-sectional regressions with results reported in Table 5. Variables are also described in Table 5.

\begin{tabular}{lrrrrrrrr}
\hline & Min & Mean & Median & Max & St.dev. & Skewness & Kurtosis & N \\
\hline Individuals & & & & & & & & \\
& & & & & & & & \\
& -0.91 & 0.00 & -0.01 & 1.13 & 0.36 & 0.06 & 1.97 & 444,704 \\
Excess buy/sell & -6.04 & 0.00 & -0.04 & 3.91 & 0.58 & 0.26 & 3.18 & 444,704 \\
Excess buy/sell volume (ln) & 1.00 & 4.28 & 3.00 & 10.00 & 2.55 & 0.83 & 2.28 & 444,704 \\
Sunniness (index) & 0.00 & 12.47 & 12.30 & 24.00 & 5.07 & 0.05 & 1.86 & 444,704 \\
Length of the day (hours) & & & &
\end{tabular}

Nonfinancial corporations

$\begin{array}{lrrrrrrrr}\text { Excess buy/sell } & -1.02 & 0.00 & 0.01 & 1.06 & 0.39 & -0.08 & 1.66 & 128,718 \\ \text { Excess buy/sell volume (ln) } & -5.36 & 0.00 & -0.07 & 3.24 & 0.57 & 0.43 & 3.68 & 128,718 \\ \text { Sunniness (index) } & 1.00 & 4.33 & 3.00 & 10.00 & 2.57 & 0.79 & 2.21 & 128,718 \\ \text { Length of the day (hours) } & 0.00 & 12.27 & 12.02 & 24.00 & 4.98 & 0.10 & 1.87 & 128,718\end{array}$

Financial corporations

$\begin{array}{lrrrrrrrr}\text { Excess buy/sell } & -1.04 & 0.00 & -0.01 & 1.03 & 0.39 & 0.06 & 1.76 & 20,612 \\ \text { Excess buy/sell volume (ln) } & -6.84 & 0.00 & -0.08 & 3.44 & 0.56 & 0.33 & 5.50 & 20,612 \\ \text { Sunniness (index) } & 1.00 & 4.34 & 3.00 & 10.00 & 2.57 & 0.79 & 2.21 & 20,612 \\ \text { Length of the day (hours) } & 1.34 & 12.42 & 12.29 & 24.00 & 4.79 & 0.03 & 1.73 & 20,612 \\ & & & & & & & & \end{array}$


Table 5

\section{Results from cross-sectional regressions for SAD and Sunniness}

This table presents results for the binomial z-test for the impact of amount of Sunniness (from 1 to 10) and Length of day (the number of hours between sunset and sunrise) on the investor group. The unit of observation is municipality and day/week. The dependent variable excess buy/sell or ln (number of trades) (See Section 3 for exact variable descriptions) is regressed on Sunniness or Length of day and a constant. The z-test statistic is computed with the binomial test as (\% of positive coefficients when regressing buy/sell ratio on Sunniness or Length of day for each municipality $-50 \%) /(0.5 * 0.5 / \text { Number of observations in the regression })^{0.5}$. The sample period runs from January 1 , 1995 through November 28, 2002.*,**, and *** denote significance (2-tailed) at 10\%, 5\%, and 1\% levels, respectively.

\begin{tabular}{|c|c|c|c|c|c|c|c|}
\hline \multicolumn{8}{|c|}{ Panel A: Weekly regressions } \\
\hline & & \multicolumn{2}{|c|}{ Individual } & \multicolumn{2}{|c|}{ Nonfin. corp. } & \multicolumn{2}{|c|}{ Fin. corp. } \\
\hline \multicolumn{2}{|l|}{$\begin{array}{l}\text { Independent } \\
\text { variable }\end{array}$} & Buy/sell & $\begin{array}{l}\text { Ln (\# of } \\
\text { trades) }\end{array}$ & Buy/sell & $\begin{array}{l}\text { Ln (\# of } \\
\text { trades) }\end{array}$ & Buy/sell & $\begin{array}{l}\text { Ln (\# of } \\
\text { trades) }\end{array}$ \\
\hline \multirow[t]{3}{*}{ Sunniness } & $\begin{array}{l}\text { \# of regressions } \\
\text { during weeks } 1-53 \\
\% \text { of positive }\end{array}$ & 403 & 403 & 403 & 403 & 403 & 403 \\
\hline & coefficients & $47.1 \%$ & $49.1 \%$ & $50.6 \%$ & $49.1 \%$ & $54.1 \%$ & $52.4 \%$ \\
\hline & $\begin{array}{l}z \text {-test } \\
\text { total \# of } \\
\text { municipality/week } \\
\text { observations }\end{array}$ & 134,502 & 134,502 & 52,333 & 52,333 & 9,748 & 9,748 \\
\hline \multirow[t]{3}{*}{ Length of day } & $\begin{array}{l}\text { \# of regressions } \\
\text { during weeks } 1-53 \\
\text { ex } 12-14 \text { and } 38-40 \\
\% \text { of positive }\end{array}$ & 356 & 356 & 356 & 356 & 356 & 356 \\
\hline & coefficients & $52.2 \%$ & $50.8 \%$ & $53.1 \%$ & $56.2 \%$ & $48.6 \%$ & $55.3 \%$ \\
\hline & $\begin{array}{l}z \text {-test } \\
\text { total \# of } \\
\text { municipality/week } \\
\text { observations }\end{array}$ & 130,720 & 130,720 & 52,255 & $2.33 * *$ & -0.53 & $2.01 * *$ \\
\hline
\end{tabular}




\begin{tabular}{|c|c|c|c|c|c|c|c|}
\hline \multicolumn{8}{|c|}{ Panel B: Daily regressions } \\
\hline \multirow[b]{2}{*}{$\begin{array}{l}\text { Independent } \\
\text { variable }\end{array}$} & \multirow{4}{*}{$\begin{array}{l}\text { \# of regressions } \\
\text { during weeks } 1-53 \\
\% \text { of positive } \\
\text { coefficients }\end{array}$} & \multicolumn{2}{|c|}{ Individual } & \multicolumn{2}{|c|}{ Nonfin. corp. } & \multicolumn{2}{|c|}{ Fin. corp. } \\
\hline & & Buy/sell & $\begin{array}{c}\text { Ln (\# of } \\
\text { trades) }\end{array}$ & Buy/sell & $\begin{array}{l}\text { Ln }(\# \text { of } \\
\text { trades })\end{array}$ & Buy/sell & $\begin{array}{c}\text { Ln (\# of } \\
\text { trades) }\end{array}$ \\
\hline \multirow[t]{3}{*}{ Sunniness } & & 1918 & 1918 & 1918 & 1918 & 1915 & 1915 \\
\hline & & $49.4 \%$ & $48.6 \%$ & $49.5 \%$ & $49.0 \%$ & $46.5 \%$ & $45.8 \%$ \\
\hline & $\begin{array}{l}z \text {-test } \\
\text { total \# of } \\
\text { municipality/day } \\
\text { observations }\end{array}$ & 444,704 & 444,704 & 128,718 & 128,718 & $-3.04 * * *$ & $-3.68^{* * *}$ \\
\hline \multirow[t]{3}{*}{ Length of day } & $\begin{array}{l}\text { \# of regressions } \\
\text { during weeks 1-53 } \\
\text { ex } 12-14 \text { and } 38-40\end{array}$ & 1694 & 1694 & 1694 & 1694 & 1693 & 1693 \\
\hline & coefficients & $52.9 \%$ & $55.3 \%$ & $51.3 \%$ & $58.9 \%$ & $47.3 \%$ & $57.4 \%$ \\
\hline & $\begin{array}{l}z \text {-test } \\
\text { total \# of } \\
\text { municipality/day } \\
\text { observations }\end{array}$ & $2.38 * *$ & $4.32 * * *$ & 133,611 & $7.34^{* * *}$ & $-2.21 * *$ & $6.05^{* * *}$ \\
\hline
\end{tabular}


Table 6

Results from cross-sectional regressions with top-quintile Sunniness variation

This table presents results for the binomial $z$-test for the impact of amount of Sunniness (from 1 to 10) for top quintile of observation days with most cross-sectional variation in the actual amount of sunlight. The unit of observation is municipality and day. The specification is identical to Table 5 . The sample period runs from January 1, 1995 through November 28, 2002.*,**, and *** denote significance (2-tailed) at 10\%, 5\%, and 1\% levels, respectively.

Daily regressions

Independent

variable

\begin{tabular}{l|l} 
Sunniness & \# of regressions during \\
weeks 1-53 \\
Percentage of positive \\
z-test \\
total \# of \\
municipality/day \\
observations
\end{tabular}

\begin{tabular}{|c|c|c|c|c|c|}
\hline \multicolumn{2}{|c|}{ Individual } & \multicolumn{2}{|c|}{ Nonfin. corp. } & \multicolumn{2}{|c|}{ Fin. corp. } \\
\hline Buy/sell & $\begin{array}{l}\text { Ln (\# of } \\
\text { trades) }\end{array}$ & Buy/sell & $\begin{array}{c}\text { Ln (\# of } \\
\text { trades) }\end{array}$ & Buy/sell & $\begin{array}{c}\text { Ln (\# of } \\
\text { trades) }\end{array}$ \\
\hline 361 & 361 & 361 & 361 & 315 & 315 \\
\hline $52.6 \%$ & $46.8 \%$ & $51.2 \%$ & $46.5 \%$ & $52.2 \%$ & $53.9 \%$ \\
\hline 1.00 & -1.21 & 0.47 & -1.32 & 0.84 & 1.48 \\
\hline 86,236 & 86,236 & 25,535 & 25,535 & 4,157 & 4,157 \\
\hline
\end{tabular}


Table 7

\section{Results from cross-sectional regressions for SAD by gender}

This table presents results for the binomial $z$-test for the impact of the length of day on trades by individual investors by gender. The unit of observation is municipality and day/week. The specification is identical to Table 5. The sample period runs from January 1, 1995 through November 28, 2002.*,** and *** denote significance (2-tailed) at 10\%, 5\% and $1 \%$ levels.

Panel A: Weekly regressions

$\begin{aligned} & \text { Independent } \\ & \text { variable }\end{aligned}$
$\begin{aligned} & \text { Length of day } \\ & \begin{array}{l}\text { \# of regressions during } \\ \text { weeks 1-53 ex 12-14 and } \\ 38-40\end{array} \\ & \text { Percentage of positive } \\ & z \text {-test } \\ & \text { total \# of } \\ & \text { municipality/week } \\ & \text { observations }\end{aligned}$

\begin{tabular}{lllll}
\multicolumn{2}{c}{ Males } & & \multicolumn{2}{c}{ Females } \\
\cline { 1 - 1 } Buy/sell & $\begin{array}{c}\text { Ln (\# of } \\
\text { trades) }\end{array}$ & & Buy/sell & $\begin{array}{c}\text { Ln (\# of } \\
\text { trades) }\end{array}$ \\
\hline & & & \\
356 & 356 & 356 & 356 \\
$53.1 \%$ & $44.4 \%$ & & $48.9 \%$ & $48.6 \%$ \\
1.17 & $-2.12 * *$ & & -0.42 & -0.53 \\
& & & \\
106,015 & 106,015 & 50,645 & 50,645
\end{tabular}

Panel B: Daily regressions

Independent

variable
\# of regressions during weeks 1-53 ex. 12-14 and $38-40$

Percentage of positive

$z$-test

total \# of

municipality/day

observations

\begin{tabular}{cccc} 
Males & & \multicolumn{2}{c}{ Females } \\
\cline { 1 - 1 } \cline { 5 - 6 } Buy/sell $\begin{array}{c}\text { Ln (\# of } \\
\text { trades) }\end{array}$ & & Buy/sell $\begin{array}{c}\text { Ln (\# of } \\
\text { trades) }\end{array}$ \\
\hline
\end{tabular}

$\begin{array}{llll}1694 & 1694 & 1694 & 1694 \\ 51.4 \% & 55.3 \% & 51.9 \% & 55.3 \% \\ 1.17 & 4.37 * * * & 1.55 & 4.37 * * * \\ & & & \\ 414,317 & 414,317 & 216,226 & 216,226\end{array}$




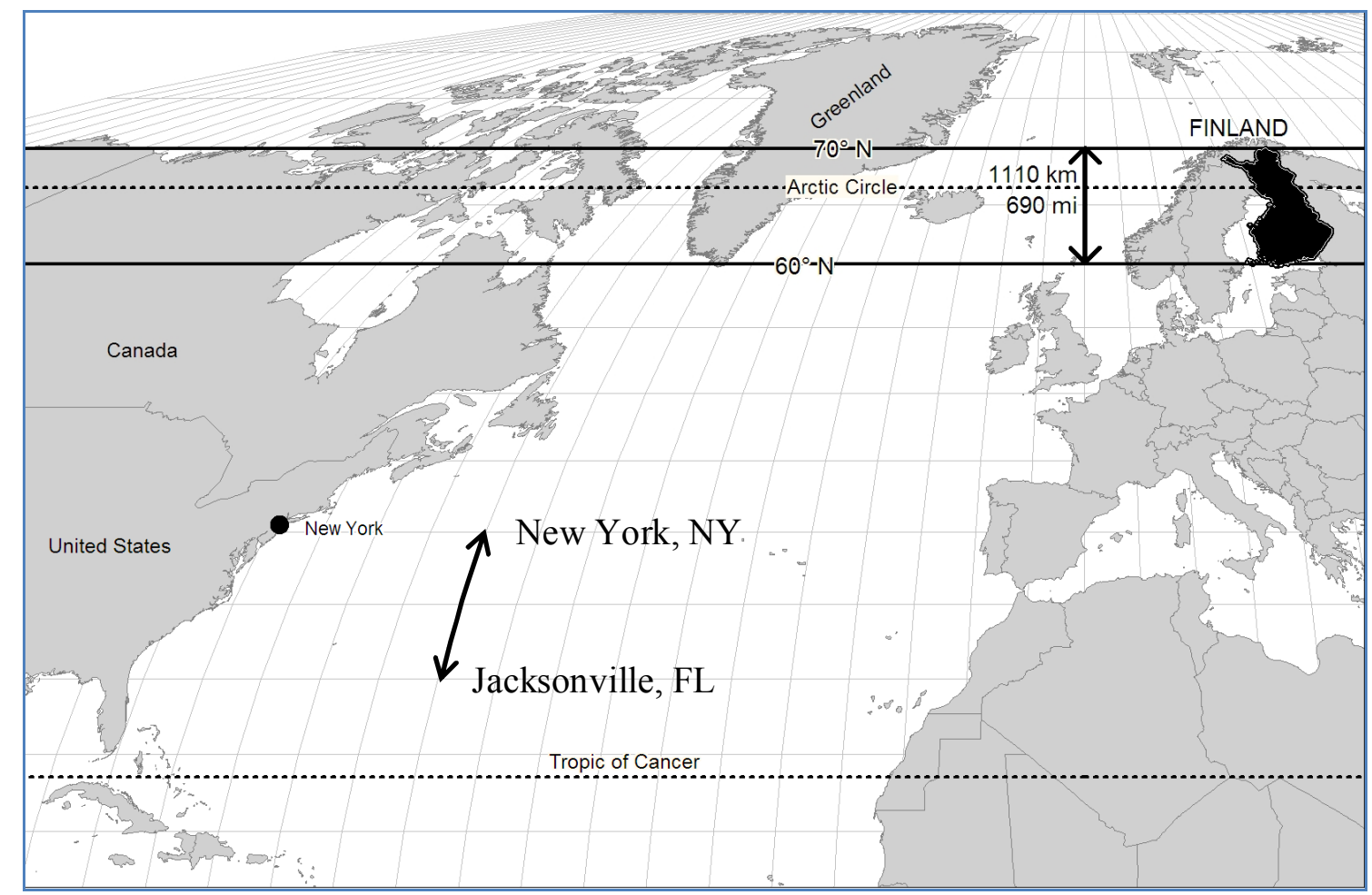

Figure 1. Location of Finland. This figure depicts the Mollweide projection (priority on accurate representation of area rather than direction) of Finland, Europe and eastern United States. The vertical distance from the southern tip to the northern tip of Finland (1,110 kilometers, or 690 miles) is approximately equal to the vertical distance from Jacksonville Florida to the New York City. 

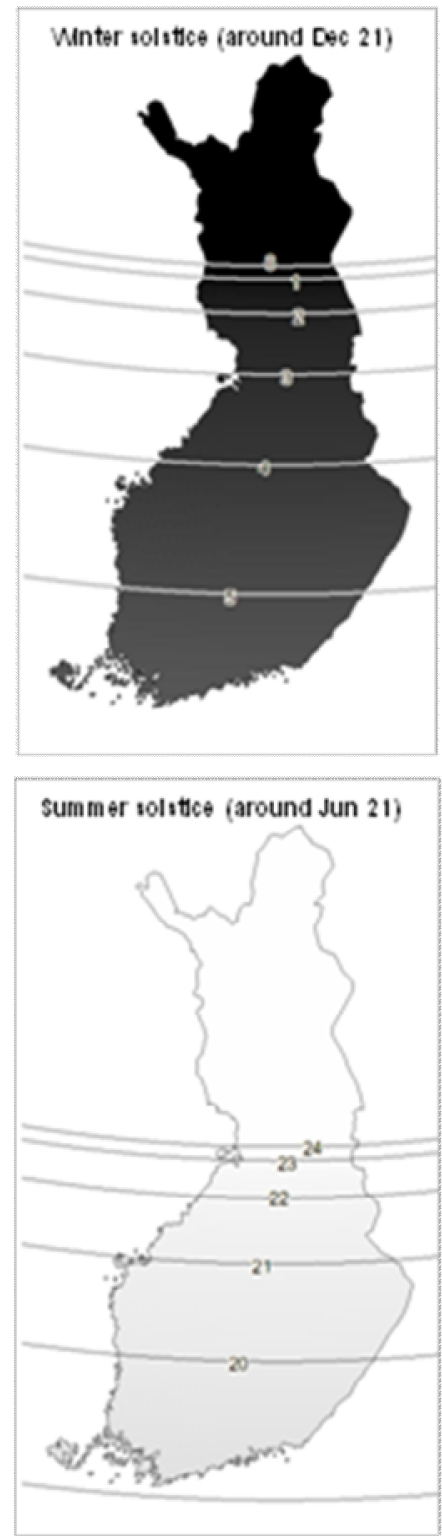

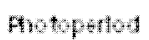

Howt

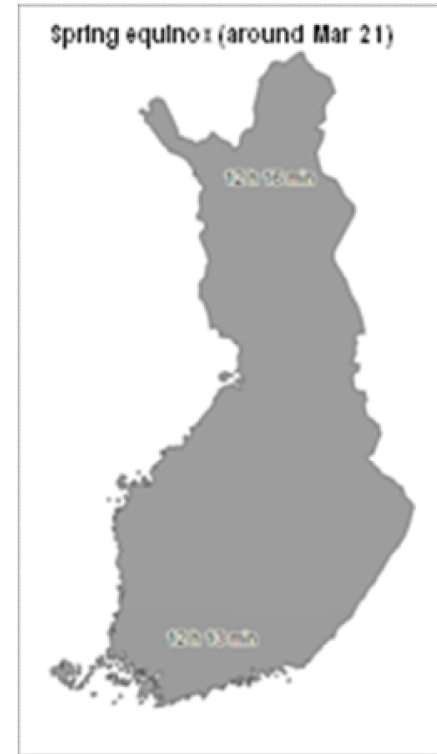

Fall equilno: (around Sẹp 21)

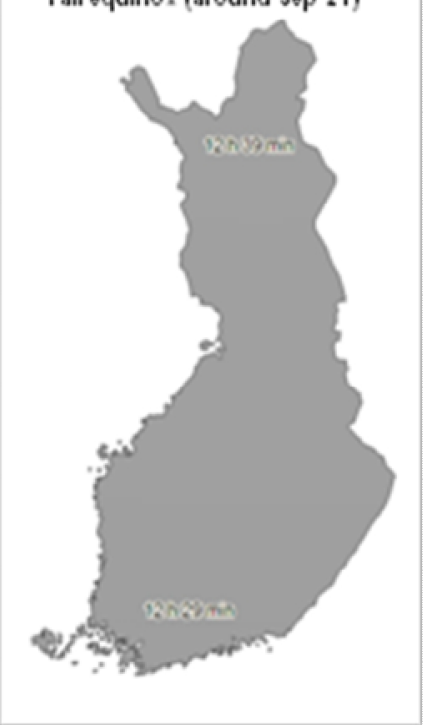

10

Figure 2. Length of day (number of hours between sunset and sunrise) during winter solstice, spring equinox, summer solstice and fall equinox. The four maps show the length of day in hours with isocurves marking the line for exact hours during the time. 
Individuals

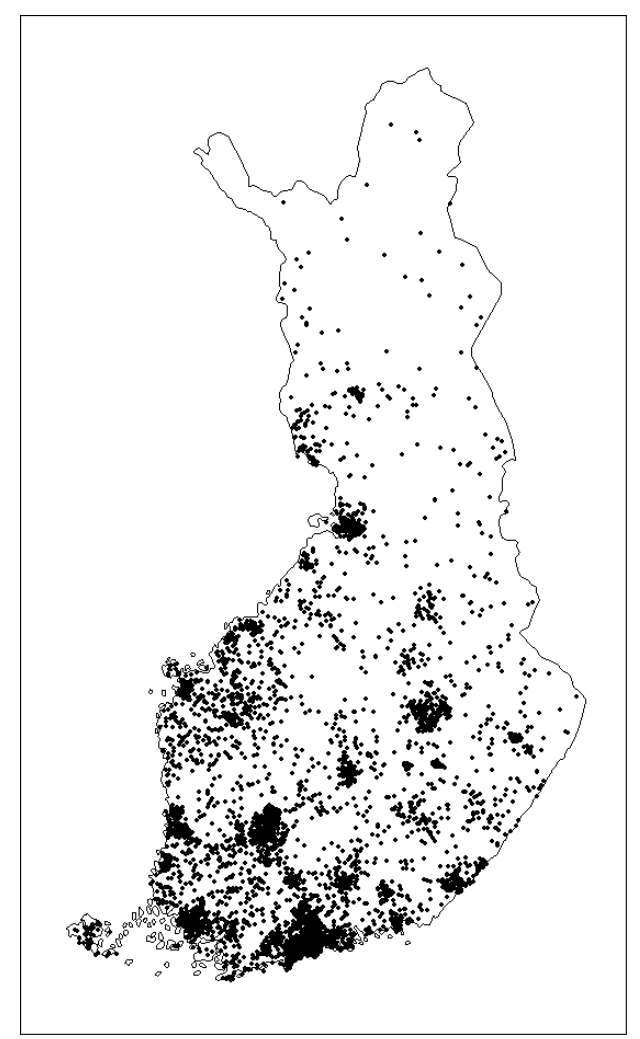

Institutions

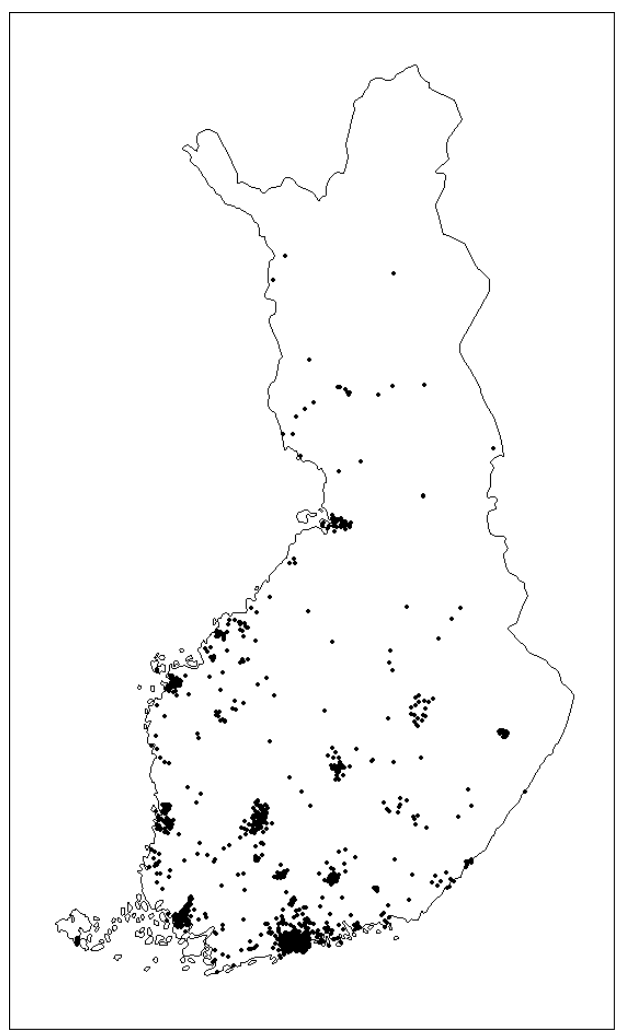

Figure 3. Geographical representation for the number of trades in the sample. The left-hand graph plots the number of trades for domestic individual investors with one dot representing 1,000 trades over the sample period from January 1, 1995 through November 28, 2002. The right-hand figure plots the number of trades for domestic institutional investors with all institutional investors pooled into one sample. 
Panel A: Whole Finland (59.9-69.7 degrees northern latitude)
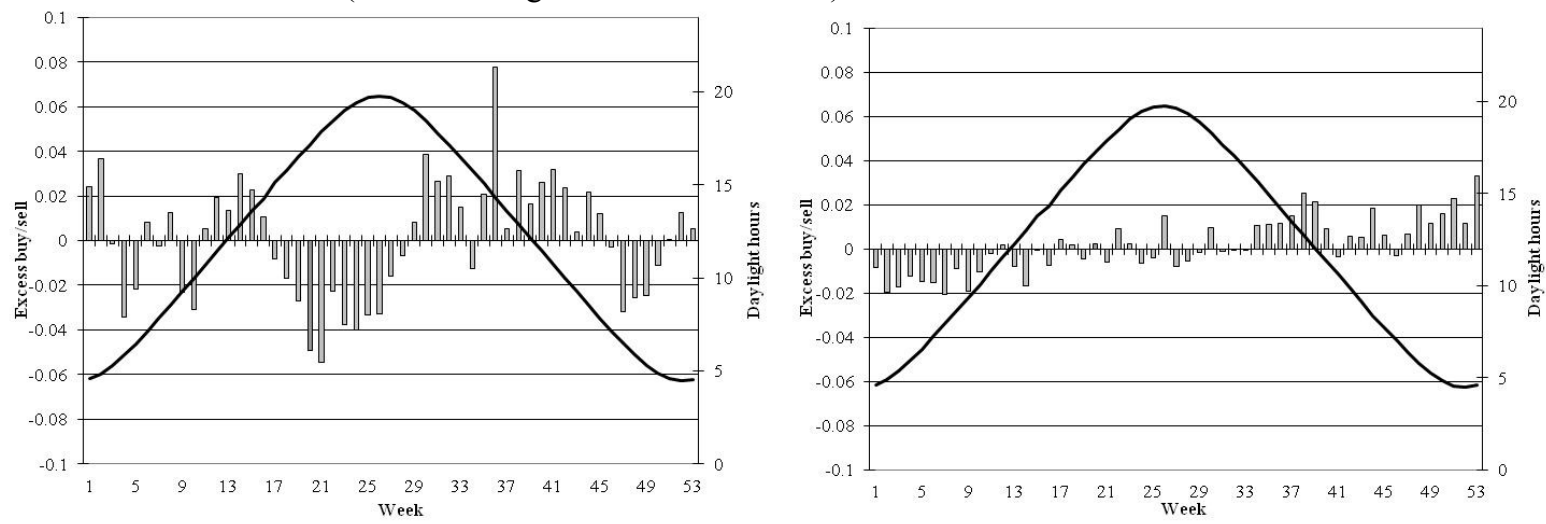

Panel B: Northern Finland (more than 64 degrees latitude)
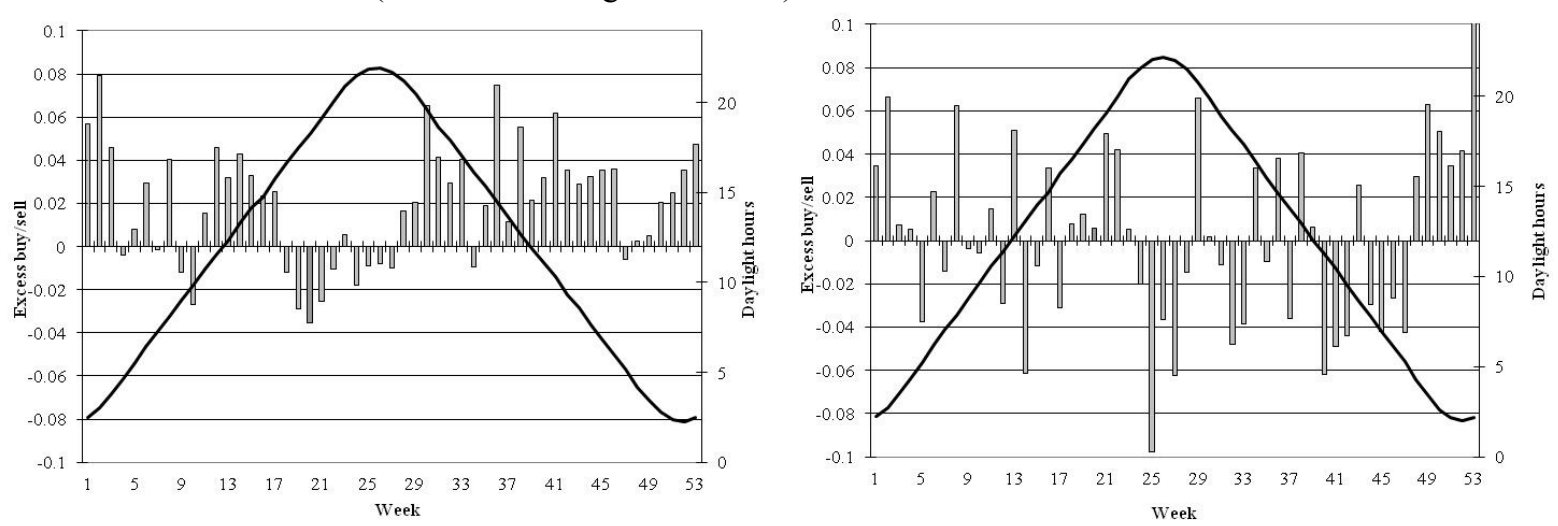

Panel C: Southern Finland (less than 62 degrees northern latitude)
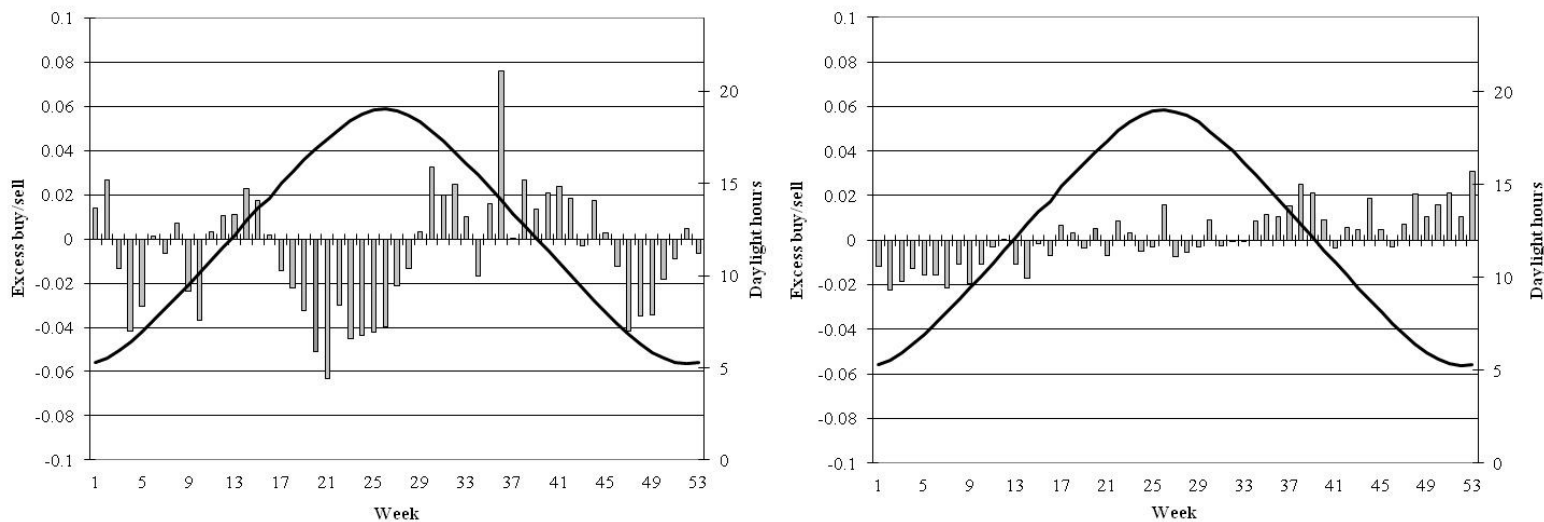

Figure 4. Daylight and excess buy/sell ratio. The excess buy/sell ratio is defined as weekly \# of buys/( weekly \# of buys + weekly \# of sells) - annual \# of buys/( annual \# of buys + annual \# of sells). The data include all transactions by domestic investors in Finland. The number of trades for calculating each graph are 8,405,166 (individuals in the whole country; also including individuals with unknown domicile); 6,262,902 (individuals in southern Finland); 666,987 (individuals in northern Finland); 6,539,397 (institutions in the whole country); 6,200,096 (institutions in southern Finland) and 80,496 (institutions in northern Finland). 


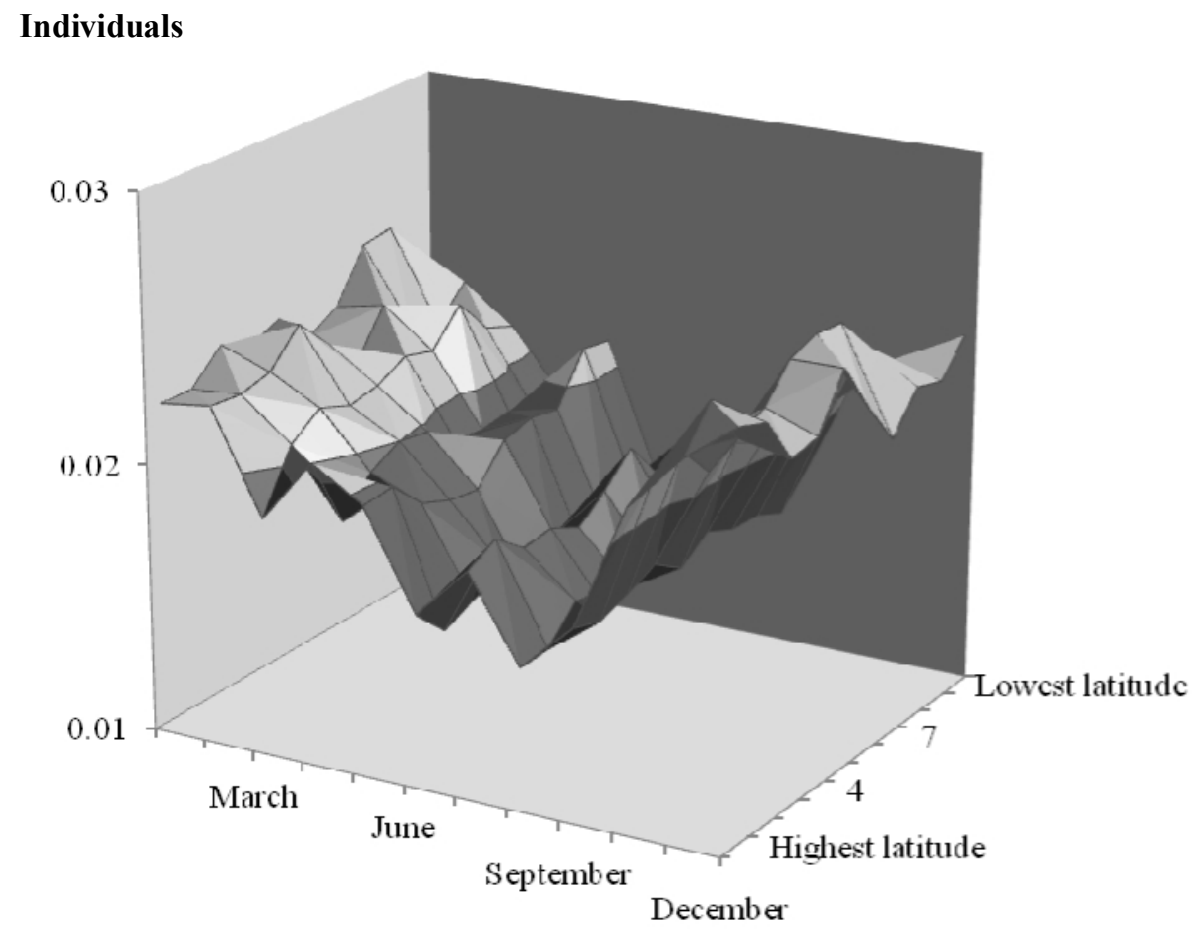

\section{Institutions}

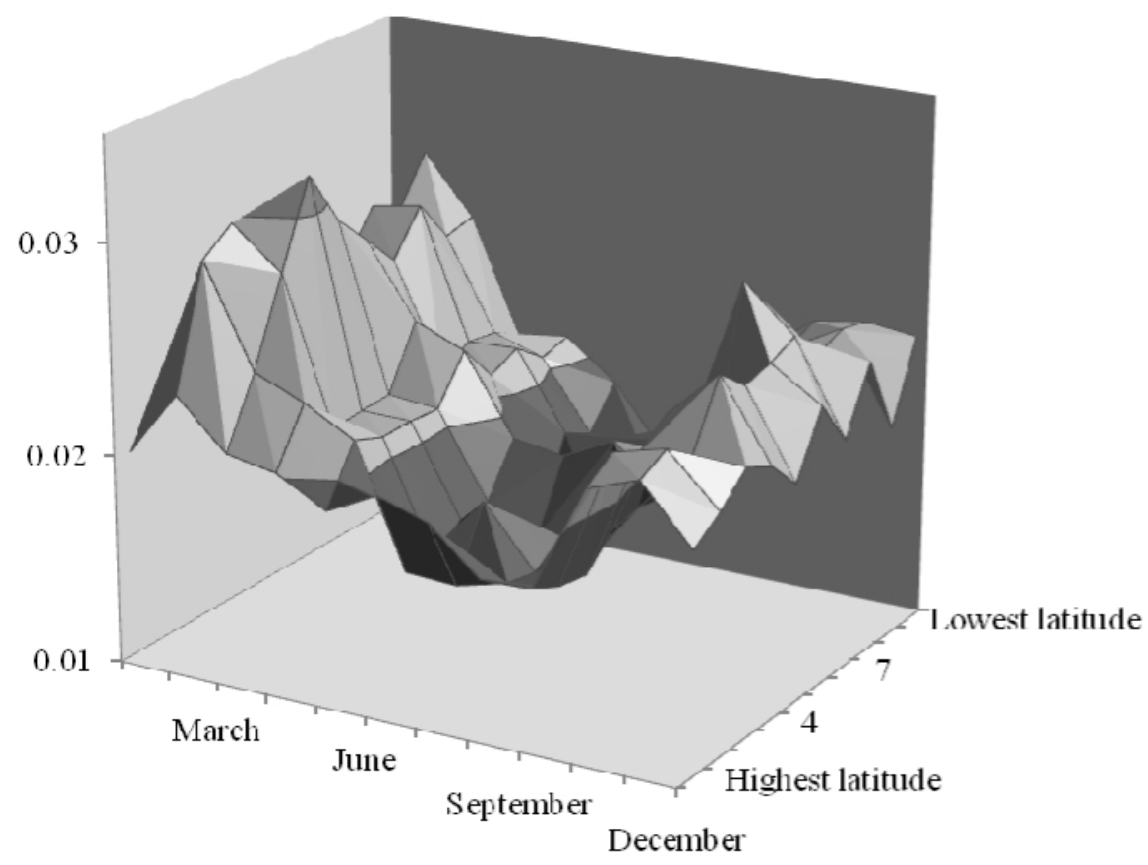

Figure 5. Excess volume ratio (weekly number of trades/annual number of trades) by month and latitude, based on all transactions by domestic investors in Finland. The number of observations is 170,872 for households and 12,257 for institutions. 
Panel A: Northern Finland (more than 64 degrees latitude)

\section{Individuals}

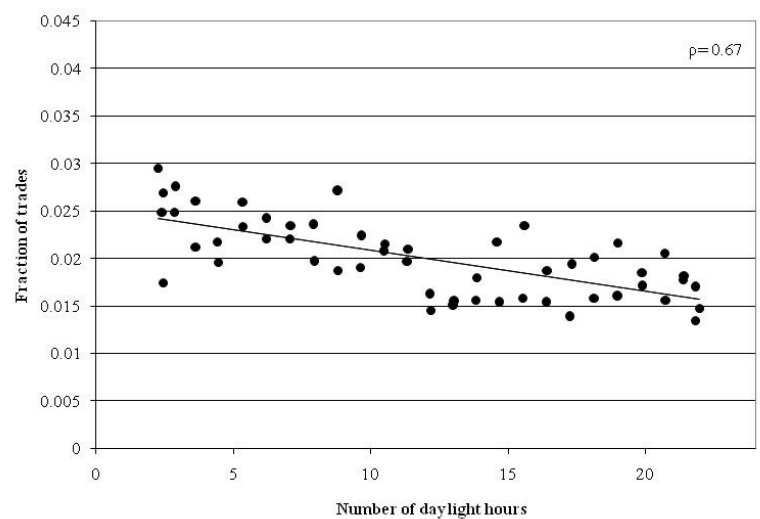

Panel B: Southern Finland (less than 62 degrees latitude)

\section{Individuals}

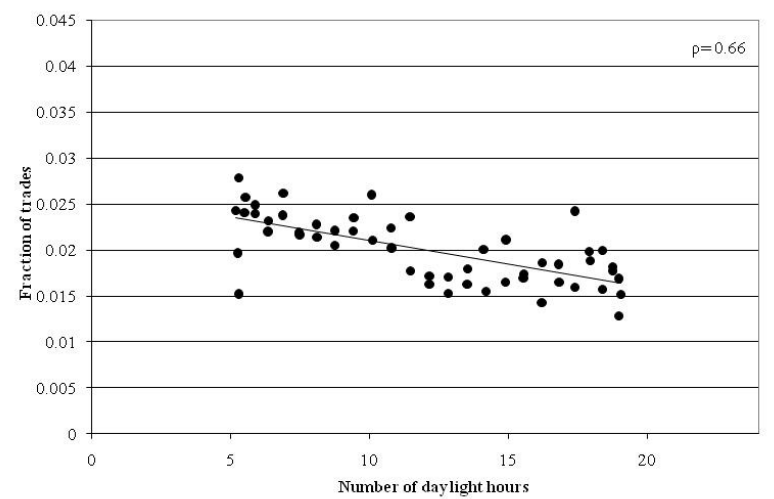

\section{Institutions}

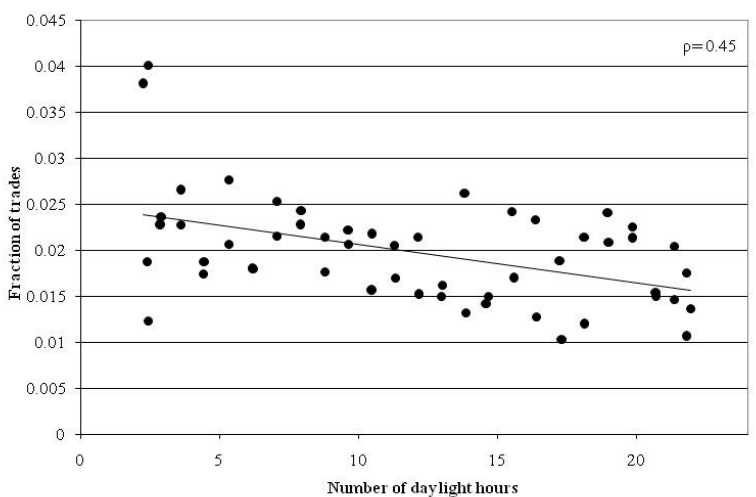

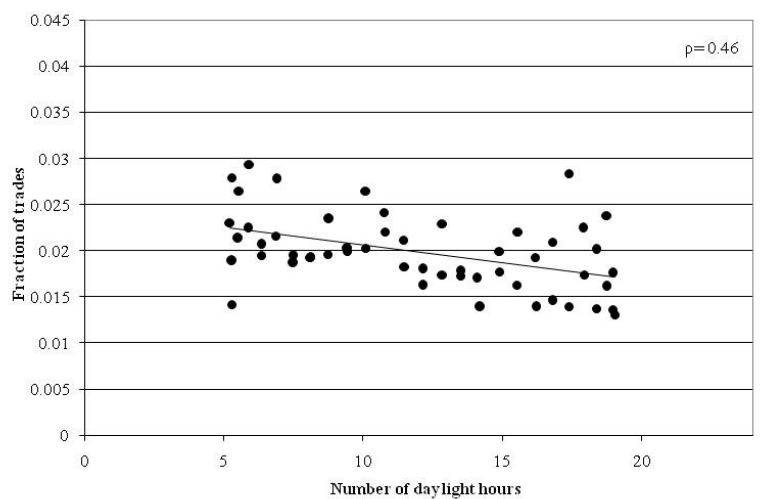

Figure 6. Daylight and volume. The plotted fraction volume is defined as weekly number of trades/annual number of trades. The analysis includes all transactions by domestic investors in Finland. The scatterplot observations represent the average weekly volume fractions of annual volume. The averages are calculated from daily observations by averaging over each week and municipality. The number of observations for the four figures are 76,958 (individuals, southern Finland); 20,740 (individuals, northern Finland); 45,950 (institutions, southern Finland); and 7,570 (institutions, northern Finland). 


\section{Recent Issues}

No. 3 Markku Kaustia - Antti

Lehtoranta - Vesa Puttonen

No. 2 Markku Kaustia - Samuli Knüpfer - Sami Torstila

No. 1 Dimitris Georgarakos - Michalis Haliassos - Giacomo Pasini
Does sophistication affect long-term return expectations? Evidence from financial advisers' exam scores

Stock Ownership and Political Behavior: Evidence from Demutualization

Household Debt and Social Interaction 